\title{
Resúmenes Tesis: Doctorado en Ciencias Biológicas
}

\section{Desarrollo y evaluación nutricional de alimentos elaborados a base de granos enteros de arroz. Efectos de los procesos de remojo, germinación y extrusión sobre el contenido y disponibilidad de nutrientes}

\section{Micaela Albarracín \\ malbarracin@fiq.unl.edu.ar \\ Director: Dra. Silvina Drago \\ Co-Director: Ing. Rolando José González \\ Lugar de realización: Instituto de Tecnología de Alimentos (ITA). LABORATORIO Cerea- les y Oleaginosas. Facultad de Ingeniería Química. Universidad Nacional del Litoral Fecha de defensa: 13 de marzo de 2015}

\section{Resumen}

El objetivo general de la tesis fue obtener productos e ingredientes a base de arroz entero utilizando procesos de remojo, germinación y extrusión y estudiar el efecto de su consumo en animales de experimentación.

El arroz constituye uno de los principales alimentos básicos de más de la mitad de la población mundial. Es el producto de la semilla de la planta Oryza sativa L., cuyo fruto es una cariópside elíptica, o grano, rodeado de brácteas escamosas que forman una cáscara seca alrededor de la semilla. La producción argentina representa menos del $1 \%$ de la producción mundial (aproximadamente 1,5 millones de toneladas) y en Argentina es el tercer cereal más producido para consumo humano, luego del maíz y del trigo. En los últimos años, se han añadido recomendaciones sobre el consumo de grano entero (GE) a las directrices dietéticas generales de muchos países. Los GE están vinculados con un menor riesgo de obesidad o aumento de peso; menor riesgo de enfermedad cardiovascular (incluyendo enfermedades coronarias, hipertensión y accidentes cerebro vascular), mejoran la salud intestinal y disminuyen el riesgo de cáncer del intestino superior, lo que posiblemente conlleva a un menor riesgo de cáncer colorectal y por consiguiente, menor tasa de mortalidad. Sin embargo, los GE contienen fitatos, principal forma de almacenamiento del fósforo en las semillas de las plantas, los cuales forman complejos con los minerales de la dieta, especialmente con el hierro y el zinc, y causan deficiencias minerales en los seres humanos. También tienen un impacto negativo sobre la utilización de las proteínas y de los lípidos. Existen diferentes técnicas de procesamiento, tales como remojo, germinación, malteado, fermentación y extrusión, que reducen el contenido de fitatos, mediante el aumento de la actividad de las fitasas presentes de forma natural en las semillas, por lixiviación en los medios o por hidrólisis.

Los procesos realizados redujeron significativamente el contenido de ácido fítico y mejoraron algunas características nutricionales, como la bioaccesibilidad de Fe y Zn, la capacidad antioxidante, y el contenido de compuestos fenólicos. Asimismo, pro- 
dujeron cambios en las propiedades físicas como la solubilidad y absorción de agua de los productos. Los estudios in vivo permitieron observar un menor consumo de dieta a base de GE concomitante con un menor consumo de $\mathrm{Ca}$, lo que se tradujo en una menor biodisponibilidad del $\mathrm{Ca}$ de estas dietas. Por otra parte, los efectos positivos del consumo de estos productos de GE de arroz a nivel cecal, del perfil lipídico y del estado oxidativo, confirmaron algunos efectos beneficiosos para el organismo.

\section{Summary}

Development and nutritional evaluation of whole grain rice based foods. Effects of soaking, germination and extrusion processes on nutrient content and availability

Rice is the main staple food for more than half of the world's population. In recent years, recommendations on whole grain consumption have been added to the overall dietary guidelines of many countries. WGs are linked to reduced risk of obesity or weight gain; reduced risk of cardiovascular disease (CVD); improved gut health and decreased risk of cancers of the upper gut. However, WGs contain phytates, which form complexes with dietary minerals, especially iron and zinc, and causes mineral-related deficiency in humans. They also negatively impact on protein and lipid utilization. Processing techniques, such as soaking, germination, malting, fermentation and extrusion, reduce phytate content by increasing activity of naturally present phytase, by leaching into the media or by hydrolysis. The overall objective of the thesis was to obtain products and ingredients based on whole grain rice using soaking, germination and extrusion processes and study the effect of their consumption in experimental animals. The processes performed with whole rice significantly reduced phytic acid content and improved some nutritional characteristics, such as Fe and Zn bioavailability, antioxidant capacity and phenolic content. Also, these processes produced changes in physical properties such as solubility and water absorption of the products. In vivo studies allowed observing a lower consumption of WGs diet, concomitant with lower consumption of $\mathrm{Ca}$, which resulted in a lower Ca bioavailability of these diets. Otherwise, positive effects on cecum, lipid profile and oxidative status confirm some beneficial effects of consumption of these whole grain rice products.

\section{Estudio de la rizogénesis en la propagación vegetativa monoclonal de Prosopis alba Grisebach (algarrobo blanco)}

\author{
Jonicélia Cristina Araújo Vieira de Souza \\ jaraujo@fca.unl.edu.ar \\ Director: Dr. Abelardo Carlos Vegetti \\ Co-director de Tesis: Dr. Luis Amado Mrog- \\ inski
}

Consejera: Deborah Guerra Barroso
Lugar de realización: Laboratorio de Morfología Vegetal y Ambiente y Departamento de Producción Vegetal - Facultad de Ciencias Agrarias - Universidad Nacional Del Litoral Fecha de defensa: 25 de marzo de 2015 


\section{Resumen}

El algarrobo blanco (Prosopis alba Grisebach) es una especie de gran importancia en la composición arbórea de zonas áridas y semiáridas de Sudamérica, de donde es nativa y de América del Norte, África y Asia. Posee un gran potencial para la producción de materiales forestales, que son tradicional e intensivamente empleados. Actualmente la especie es propagada comercialmente a través de semillas, sin embargo este método de propagación genera una gran variabilidad genética en las plantaciones comerciales, presentando características indeseables a la producción comercial. Por eso existe un gran interés en obtener tecnologías de propagación clonal de la especie. La propagación vegetativa de especies forestales, asociada a programas de mejoramiento, tiene como finalidad acelerar el crecimiento, aumentar la productividad y uniformidad de los plantíos comerciales. El principal objetivo de este trabajo fue evaluar la viabilidad de la propagación vegetativa a través de la técnica de miniestacas y el efecto del ácido indolbutírico (IBA) en las concentraciones de 0,3000, 4500, 6000 y $7500 \mathrm{mg} \mathrm{L}^{-1}$ sobre el enraizamiento de clones de $P$. alba. Se logró el enraizamiento de 98 a 100\% de miniestacas en las concentraciones testadas. Al aumentar la concentración de IBA se observó un incremento en el número de hojas y foliólulos de los plantines clonales, como así también, del número, longitud y peso de materia fresca de raíces hasta alcanzar su concentración óptima.

Paralelamente, se realizó la propagación a través de estacas convencionales de jardín clonal a campo, bajo las mismas condiciones de enraizamiento con el objetivo de comparar la eficiencia de las dos técnicas de propagación. Se observó mayor porcen- taje de enraizamiento y sobrevivencia de las miniestacas en relación a las estacas.

Se efectuó también un análisis de correlación entre características de las plantas madres (altura, diámetro, número de brotes) y de los propágulos (altura, diámetro) y se observó correlación positiva entre las plantas madres y los propágulos en el enraizamiento como en la altura de los brotes con: la longitud total de raíces, número de foliólulos y altura de los plantines clonales.

El trabajo también tuvo como objetivo evaluar el efecto de la época del año en el enraizamiento de miniestacas de $P$. alba.

Estudios anatómicos fueron realizados para evaluar el efecto del grado de lignificación en enraizamiento de propágulos y la presencia o no de barreras mecánicas y la influencia de las mismas en el enraizamiento.

Se propone a la técnica de miniestacas como una herramienta para la clonación de P. alba.

Palabras clave: Silvicultura clonal, Algarrobo blanco, Enraizamiento, Propagación vegetativa.

\section{Summary}

Study of the rooting of vegetative propagation monoclonal Prosopis alba Grisebach (mesquite).

Mesquite (Prosopis alba Grisebach), an important species in arid and semiarid regions is native to South America and North America, Africa and Asia, is currently commercially propagated by seeds, however this method of propagation generates a large genetic variability in commercial plantations, introducing undesirable to commercial production characteristics. So there is great interest in developing techniques 
for clonal propagation of species. The main objective of this work was to evaluate vegetative propagation using the mini-cutting technique and indolebutyric acid (IBA) at different concentrations $(0,3000,4500$, 6000 and $7500 \mathrm{mg} \mathrm{L}^{-1}$ ) on rooting of $P$. alba clones. Rooting was achieved in $98-100 \%$ of the mini-cuttings at all concentrations tested. Increasing the concentration of IBA the observed an increase in the number of leaves and leaflets of clonal seedlings, as well, fresh matter weight and in number and length of roots to reach its optimum concentration. Plants were also vegetatively propagated in the field via conventional clonal garden cuttings under the same rooting conditions to compare the efficiency of the two propagation techniques. Higher percentage of rooting and survival of minicutings was observed in relation to cuttings. The work also aimed to evaluate the effect of season on rooting miniestacas $P$. alba. Anatomical studies were performed to evaluate the effect of lignification in rooting of propagules and the presence or absence of mechanical barrier and the influence thereof on rooting. We propose the mini-cutting technique as a tool for the P. alba cloning.

Key words: Clonal forestry, Mesquite, Rooting, Vegetative propagation.

\section{Estudio de nuevos actores en el metabolismo antioxidante de protozoos patógenos}

\section{Matías Sebastián Cabeza}

matiascabeza@gmail.com

Director: Dr. Sergio Adrián Guerrero

Co-Director: Dr. Diego Gustavo Arias

Lugar de realización: Instituto de Agrobiotecnología del Litoral. Laboratorio de Bioquímica Microbiana. Facultad de Bioquímica y Ciencias Biológicas. Universidad Nacional del Litoral

Fecha de la defensa: 03/07/2015

\section{Resumen}

Las especies reactivas (EROs) generadas como subproductos del metabolismo del $\mathrm{O}_{2}$ tienen el potencial de dañar las macromoléculas celulares. Para hacer frente a estos riesgos los organismos aerobios han desarrollado mecanismos de defensa para protegerse frente a la toxici- dad de las EROs. Los organismos anaerobios, por el contrario, no utilizan $\mathrm{O}_{2}$ para producir energía. Si bien habitan usualmente ecosistemas anóxicos, no pueden evitar estar expuestos eventualmente al $\mathrm{O}_{2}$. Los caminos metabólicos presentes en los organismos anaerobios, especialmente los dependientes de flavoenzimas, tienden a transferir electrones al $\mathrm{O}_{2}$ generando de esta forma EROs. En general, los organismos anaerobios carecen de los mecanismos de defensa clásicos encontrados en los organismos aerobios y en su lugar han desarrollado otras innovaciones.

Esta Tesis se centra en el estudio de diferentes sistemas antioxidantes presentes en dos parásitos patógenos humanos. Uno de estos organismos presenta un metabolismo anaerobio (Entamoeba histolytica) mientras 
que el otro tiene un estilo de vida aerobio (Trypanosoma cruzi). Estos patógenos no solo tienen que lidiar con las EROs producidas de forma endógena, sino también con las derivadas de la respuesta inmune del huésped parasitado.

Entamoeba histolytica, un parásito intestinal que es el agente causal de la amebiosis humana, está expuesto a concentraciones elevadas de EROs durante la invasión de tejidos. La primera parte de esta tesis comprende los estudios bioquímicos realizados con el objetivo de alcanzar un mejor entendimiento de las propiedades cinéticas y estructurales de una rubredoxina reductasa (EhNROR), una proteína flavodiférrica (EhFDP1), una rubreritrina ( $E h R r)$ y dos ferredoxinas (EhFd1-2) de E. histolytica. Se completó la caracterización de dos rutas metabólicas diferentes, dedicadas a la detoxificación de $\mathrm{O}_{2} \mathrm{y}_{2} \mathrm{O}_{2}$ en E. histolytica. También se caracterizó una nueva proteína con actividad rubredoxina reductasa (EhNROR) que es capaz de catalizar la reducción $\mathrm{NAD}(\mathrm{P}) \mathrm{H}$ dependiente de rubredoxinas (Rd) heterólogas, EhRr y EhFDP1 pero no así de las EhFd1-2. Así mismo, la EhNROR exhibió actividad NAD(P)H oxidasa, la cual genera $\mathrm{H}_{2} \mathrm{O}_{2}$ utilizando $\mathrm{O}_{2}$ como sustrato. Además se dejó en evidencia que diferentes ferredoxinas son capaces de reducir eficientemente tanto a la EhFDP1 como a la EhRr.

En conclusión, los sistemas enzimáticos caracterizados podrían contribuir in vivo a la detoxificación de $\mathrm{O}_{2} \mathrm{y}_{2} \mathrm{O}_{2}$, cumpliendo una función importante en la defensa del parásito contra las EROs.

Los tripanosomátidos parasitan una amplia variedad de vertebrados e invertebrados. Se han realizado muchos esfuerzos para comprender los mecanismos mediante los cuales estos organismos son capaces de neutralizar las EROs, pero mucho menos se conoce acerca de las proteínas responsables de reparar el daño causado por estas especies reactivas. La metionina es un aminoácido susceptible de ser oxidado a metionina sulfóxido (MetSO). La reducción de MetSO a metionina es catalizada por una metionina sulfóxido reductasa (Msr), una enzima presente en casi todos los organismos. Las MsrA y las MsrB son los dos tipos de Msr mas estudiadas y reparan metionina-S-sulfóxido (Met-S-SO) y metioninaR-sulfóxido (Met-R-SO), respectivamente. Recientemente se ha descripto una Msr en Escherichia coli (EcfRMsr), específica para Met-R-SO no peptídica. Esta enzima se encuentra presente en algunos procariotas y eucariotas unicelulares. La segunda parte de esta Tesis comprende la caracterización de dos TcfRMsr alélicas presentes en el genoma diploide de Trypanosoma cruzi.

En este trabajo se llevó a cabo el clonado, la purificación y la caracterización de los dominios catalíticos ( $\mathrm{N}$-terminal) de ambos alelos de la TcfRMsr. Estos fueron capaces de reducir Met-R-SO utilizando triparredoxina como dador de electrones. La eficiencia catalítica entre ambos alelos difirió en un orden de magnitud. Esta discrepancia podría ser explicada en base a diferencias en sus estructuras cuaternarias. Así mismo, la TcfRMsr fue capaz de complementar el fenotipo de una cepa de levadura mutante en todas sus Msr endógenas, confirmando de esta forma la funcionalidad de la enzima in vivo. La TcfRMsr aparenta sufrir distintas modificaciones post-traduccionales, como por ejemplo, un corte proteolítico entre sus dos dominios constituyentes. Este proceso parece estar regulado, sin embargo la señal que lo desencadena se 
desconoce. En este sentido, la función fisiológica de las modificaciones que enfrenta la enzima aún debe ser dilucidada.

\section{Summary}

Study of new actors in the antioxidant metabolism of protozoan pathogens

This thesis focuses on the study of different antioxidant systems present in human parasites.

Entamoeba histolytica, an intestinal parasite that is the causative agent of amoebiasis, is exposed to elevated amounts of reactive oxygen species (ROS) during tissue invasion. Firstly, this thesis deals with biochemical studies performed to reach a better understanding of the kinetic and structural properties of a rubredoxin reductase (EhNROR), a flavodiiron protein (EhFDP1), a rubrerythrin (EhRr) and two ferredoxins (EhFd1-2) from E. histolytica. In addition, the enzymatic systems herein characterized could contribute to the in vivo detoxification of $\mathrm{O}_{2}$ and $\mathrm{H}_{2} \mathrm{O}_{2}$, playing a key role for the parasite defense against ROS.
Many efforts have been made to understand the mechanisms by which trypanosomatids neutralize ROS but much less are known about the proteins responsible of repairing the damage created by them. Methionine, for example, is an amino acid susceptible to be oxidized to methionine sulfoxide (MetSO). Reduction of MetSO to methionine is catalyzed by methionine sulfoxide reductase (Msr), an enzyme present in almost all organisms. MsrA and MsrB are the best known Msrs that repair methionine-S-sulfoxide (Met-S-SO) and methionine-R sulfoxide (Met-R-SO) respectively. In addition, an Escherichia coli Msr enzyme (EcfRMsr), specific for non-peptidic MetR-SO, was recently discovered. The second part of this thesis deals with the characterization of two allelic TcfRMsr present in the diploid genome of Trypanosoma cruzi. In this work, we carried out the cloning, expression, purification and enzymatic characterization of the catalytic TcfRMsr N-terminal domains of both alleles.

\section{Factores de transcripción vegetales de la familia HD-Zip: hacia la comprensión de las diferencias funcionales entre los distintos miembros a través de un análisis molecular. Estudio particular del gen AtHB1 de Arabidopsis thaliana}

\section{Matias Capella}

matiascapella@gmail.com

Director: Dra. Raquel L. Chan

Lugar de realización: Instituto de Agrobiotecnología del Litoral (CONICET/UNL). Laboratorio de Biotecnología Vegetal. Facultad de Bioquímica y Ciencias Biológicas. Universidad Nacional del Litoral

Fecha de la defensa: 25 de marzo de 2015

\section{Resumen}

Las plantas son organismos sésiles que necesitan adaptarse a los continuos cambios ambientales. La integración entre las señales ambientales y el desarrollo de las plantas está regulada principalmente a nivel transcripcional por los factores de transcripción (FTs). Entre los FTs estudiados, los que contienen un homeodominio (HD) constitu- 
yen un grupo relevante. La familia HD-Zip, exclusiva de plantas, se caracteriza por la combinación singular de un HD asociado a un cierre de leucinas, que actúa como un dominio de dimerización, un requisito para la unión al ADN. Estos FTs fueron clasificados en cuatro subfamilias (I a IV), y los miembros de la subfamilia I estudiados participan de respuestas al estrés abiótico. Los FTs HD-Zip I presentan patrones de expresión similares y unen la misma secuencia blanco de ADN; sin embargo, participan en diferentes vías de transducción de señales.

Recientemente, un análisis bioinformático reveló la existencia de motivos conservados por fuera del dominio HD-Zip, algunos de los cuales son semejantes a motivos de transactivación. En base a esto, nos planteamos corroborar o refutar la hipótesis de que los motivos conservados externos al HD-Zip en los miembros de la subfamilia I eran los responsables de la diversidad funcional, a través del estudio de sus regiones carboxilo terminales. En primer lugar, mediante ensayos de simple híbrido observamos que AtHB1, AtHB7, AtHB12 y AtHB13 exhiben la capacidad de activar la transcripción tanto en plantas como en levaduras, pero con diferentes grados. El segmento proteico necesario para tal capacidad fue diferente entre estos cuatro FTs, así como también el papel de los residuos triptófanos que poseen, y los ensayos en plántulas confirmaron la capacidad y especificidad de activación de estos motivos. Al evaluar la interacción con componentes de la maquinaria transcripcional basal mediante ensayos de doble hibrido en levaduras y ensayos de pull-down, AtHB1 fue capaz de interaccionar con TBP, AtHB12 interaccionó con TFIIB, AtHB7 interaccionó tanto con TBP como con TFIIB, mientras que AtHB13 mostró una interacción débil con ambos.

En estudios previos se había informado que AtHB1 era un activador transcripcional y que su sobreexpresión en plantas de tabaco generaba un fenotipo deetilolado constitutivo. Pero no se contaba con información adicional, por lo que decidimos hacer un estudio detallado de su función. El análisis de plantas transformadas con la región promotora de AtHB1 fusionada a un gen reportero indicó que se expresa principalmente en los hipocotilos y las raíces, y que su expresión se induce en plántulas crecidas en un régimen de día corto. Además, las plantas homocigotas mutantes knockdown presentaron hipocotilos más cortos, mientras que las sobreexpresantes de AtHB1 más largos que sus pares salvajes, especialmente en condiciones de día corto. La bibliografía indicaba que AtHB1 podía ser un blanco de Phytochrome-Interacting Factor 1 (PIF1), y el análisis de plantas mutantes en este gen junto con co-transformaciones en hojas de tabaco sugirió que PIF1 estaría regulando positivamente la expresión de AtHB1. La medición del largo de los hipocotilos en plántulas crecidas en condiciones de día corto o día largo de los genotipos mutantes athb1, pif1, athb1/pif1 y sobreexpresantes de PIF1 o AtHB1 en un fondo genético salvaje, athb1 o pif1, nos permitió corroborar que AtHB1 es un componente que actúa corriente abajo de PIF1. Finalmente, un análisis transcriptómico comparativo entre mutantes athb1 y controles salvajes reveló que AtHB1 regula varios genes involucrados en la composición y la elongación de la pared celular.

Con el objeto de adquirir un mejor conocimiento en los mecanismos que regulan la expresión de AtHB1, analizamos el efecto que tiene su región 5' no codificante 
(5'UTR, por sus siglas en inglés) en plántulas de Arabidopsis. La región 5'UTR de este gen contiene un uORF (del inglés, upstream Open Reading Frame) conservado, que para otros genes había sido implicado en la regulación de la expresión. El análisis histoquímico y fluorométrico de las plantas de Arabidopsis indicó que la expresión tanto a nivel transcripcional como traduccional es más alta en las plantas transformadas con una construcción en la que se eliminó el 5'UTR. A su vez, el tratamiento de plántulas con etileno exógeno reveló que el 5'UTR inhibe la traducción de los transcriptos de AtHB1 inducida por la hormona. La sobreexpresión de este FT generó insensibilidad al etileno en las plantas crecidas en luz.

En base a lo expuesto, pudimos concluir que la capacidad de activación diferencial de AtHB1, AtHB7, AtHB12 y AtHB13 brinda un importante nivel de divergencia funcional a estas proteínas. Por otro lado, AtHB1 actuaría corriente abajo de PIF1, promoviendo la elongación celular en el hipocotilo, especialmente en respuesta a condiciones de día corto. Finalmente, el 5'UTR regula negativamente la expresión de AtHB1 e inhibe la inducción traduccional mediada por el etileno de este FT, el cual cumple un papel negativo en el crecimiento del hipocotilo promovido por esta fitohormona en luz.

\section{Summary}

Plant homeodomain-leucine zipper transcription factors: toward the understanding of functional differences between the different members through a molecular analysis. Particular characterization of the Arabidopsis thaliana gene AtHB1

Homeodomain-leucine zipper (HD-Zip) proteins are transcription factors (TF) unique to plants, classified in four subfamilies. Subfamily I members have been mainly associated to abiotic stress responses. The functional characterization of several members indicated that they take part in different signal transduction pathways even when their expression patterns are similar and they have high binding affinity for the same DNA sequence. A recent bioinformatic analysis revealed the existence of conserved motifs outside the HD-Zip domain, including putative transactivation motifs. We demonstrated that AtHB1, AtHB7, AtHB12 and AtHB13 exhibited activation activities in yeast and plants but with different degrees, and the protein segment necessary for such activation is different for these proteins. Furthermore, these TFs differentially interact with TBP2 and TFIIB. Their differential activation ability significantly contributes to the functional divergence presented by these HD-Zip I proteins, and together with their expression patterns, these differences could explain, at least in part, such functional divergence. Furthermore, AtHB1 is a HD-Zip I TF described as a transcriptional activator with unknown function and its role in Arabidopsis thaliana development was investigated. AtHB1 is mainly expressed in hypocotyls and roots and up-regulated in seedlings grown under a short-day photoperiod. We demonstrated that this TF would act downstream of PIF1 to regulate growth-related proteins expression, thus promoting hypocotyl cell elongation, especially in response to short-day photoperiod. Finally, a conserved 5'UTR negatively regulates AtHB1 expression and inhibits ethylene-translation induction of this TF, which in place would be playing a negative role in ethylene-promoted hypocotyl growth in light. 
Biología reproductiva de Ziziphus mistol Griseb. (Rhamnaceae) y Vasconcellea quercifolia A. St.-Hil. (Caricaceae): dos especies arbóreas nativas del centronorte de Argentina

\section{María Carolina Cerino}

mccerino@fca.unl.edu.ar

Director: Dr. Juan Pablo Torretta; Co-Director: Dr. Pablo Andrés Tomas

Cátedra de Botánica Sistemática Agronómica, Departamento de Biología Vegetal. Facultad de Ciencias Agrarias. Universidad Nacional del Litoral

Fecha de la defensa: 30 de marzo de 2015

\section{Resumen}

El objetivo de este trabajo fue evaluar la biología reproductiva de Ziziphus mistol Griseb. y Vasconcellea quercifolia A. St.Hil., dos especies arbóreas nativas de los bosques chaqueños del centro y norte de Argentina. Ambas poseen características -frutos comestibles, compuestos biológicamente activos, resistencia a frío, sequía, salinidad- y una amplia variedad de usos que las convierten en interesantes recursos genéticos para su conservación y domesticación. El estudio abarcó aspectos de fenología reproductiva, biología floral, visitantes florales y sistema reproductivo. El estado fenológico fue descripto en función del inicio, pico y fin de floración y fructificación. La caracterización de biología floral comprendió la determinación y descripción morfológica del morfo sexual, longevidad floral y recompensas. El elenco de visitantes florales fue caracterizado por medio de observaciones directas del comportamiento de forrajeo y duración de visitas; capturas de insectos con redes entomológicas y posterior identificación. El sistema reproductivo fue evaluado a través de los siguientes tratamientos: a) Polinización abierta (control), b) Anemofilia, c) Polinización cruzada manual (alogamia), d) Auto-polinización autónoma (auto-polinización espontánea dentro de la flor)/Apomixis, y e) Polinización autógama manual (auto-compatibilidad). Los muestreos se realizaron en una población de cada especie ubicada en Colonia La Brava, Departamento San Javier, Provincia de Santa Fe (3051'08.63'S, 6015'56.37'O). Ambas poblaciones fueron monitoreadas durante cuatro temporadas reproductivas consecutivas entre los años 2010 y 2014. Los resultados indicaron que Z. mistol y $V$. quercifolia son especies xenógamas, y que requieren de polinizadores para la formación de frutos y semillas; mostrando a su vez rasgos reproductivos contrastantes. En Z. misto/ la duración media de floración de cada individuo fue de 47,5 \pm 3,5 días, y el período de floración de los mismos fue altamente sincronizado; sus flores hermafroditas exhibieron dicogamia protándrica sincronizada, ofrecieron polen y néctar como recompensas, y sus visitantes más frecuentes fueron avispas de los géneros Brachygastra y Polistes. La formación de frutos ocurrió principalmente por polinización cruzada, pero también se desarrollaron frutos por auto-polinización. Por otro lado, se observó que $V$. quercifolia es una espe- 
cie dioica tanto morfológica como funcionalmente. Presentó dimorfismo sexual en la extensión de la floración, número de flores abiertas por inflorescencia, tamaño de flor y recompensa floral. El período de floración de los individuos femeninos abarcó $55,72 \pm 15,21$ días, mientras que en los masculinos fue de 77,5 $\pm 16,5$ días. Además de presentar una floración más extendida que los individuos femeninos, los masculinos también exhibieron mayor número de flores abiertas por inflorescencia, y flores de menor tamaño que las femeninas. Los principales visitantes florales estuvieron representados por polillas de las familias Noctuidae y Pyralidae. El presente estudio demuestra por primera vez el comportamiento reproductivo de $Z$. mistol y $V$. quercifolia, lo cual constituye un conocimiento fundamental para el desarrollo de programas de manejo, conservación y domesticación de estas especies nativas.

\section{Summary}

Reproductive biology of Ziziphus mistol Griseb. (Rhamnaceae) and VasconceIlea quercifolia A. St.-Hil. (Caricaceae): two native tree species from north-central of Argentina

The aim of this study was to evaluate the reproductive biology of Ziziphus mistol and Vasconcellea quercifolia, two native trees that inhabit the Chaco forests of central and northern Argentina. Both have features - edible fruits, biologically active compounds, resistance genes to abiotic stress conditions- and a wide variety of uses that make them attractive as potential genetic resources for conservation and domestication. The study covered aspects of reproductive phenology, floral biology, floral visitors and breeding system. The phenological stage was described in terms of onset, peak and finish of flowering and fruiting. Floral biology was characterized by morphological description of the sexual morph, floral longevity and floral rewards; floral visitors were captured using entomological nets when visiting flowers, prepared as per conventional techniques and identified. To evaluate the breeding system manipulative experiments were performed: a) Open-pollination (control), b) Anemophily, c) Hand crosspollination (alogamy), d) Autonomous selfpollination (spontaneous within-flower selfing)/Apomixis, and e) Hand self-pollination (self-compatibility). Sampling was conducted in one population of each species located in Colonia La Brava (3051'08.63'S, $\left.60^{\circ} 15^{\prime} 56.37^{\prime \prime} \mathrm{O}\right)$, Santa Fe province. Both populations were monitored during four consecutive reproductive seasons from 2010 to 2013. Our results showed that Z. mistol and $V$. quercifolia are alogamous species, and require pollinators for the formation of fruits and seeds, and they have contrasting reproductive traits. The mean flowering duration of the Z. mistol individuals were $47,5 \pm 3,5$ days, and blooming period of individuals was highly synchronous; their hermaphrodite flowers exhibited synchronous protandrous dichogamy, they offered pollen and nectar as rewards, and more frequent floral visitors were wasps of the genera Brachygastra and Polistes. Fruit set was mainly by cross-pollination, but it also occurred under selfing. On the other hand, was observed that $V$. quercifolia is both morphologically and functionally a dioecious species. Sexual dimorphism was pronounced in length of flowering, number of open flowers per inflorescence, floral size and rewards. The flowering period of female individuals comprised $55,72 \pm 15,21$ days, while in males it was 
of $77,5 \pm 16,5$ days. In addition to having a more extended flowering than female individuals, male individuals also have a greater number of open flowers per inflorescence, and smaller flowers than females. Main floral visitors were moths belonging Noctuidae and Pyralidae family. The present shows for the first time the reproductive behavior of $Z$. mistol and $V$. quercifolia which represents a fundamental knowledge for development of management, conservation and domestication programs in these species.

\section{Estrategias tecnológicas para el incremento de la proteólisis y peptidólisis de quesos duros}

\section{Luciana Maria Costabel}

costabel.luciana@inta.gob.ar

Director / Co-Director: Dra. Erica Hynes/ Dr. Sergio Vaudagna

Lugar de realización: INTA EEA RAFAELA, INLAIN (UNL/CONICET), ITA CASTELAR. Laboratorio de Calidad de Leche y Agroindustria, INTA EEA Rafaela; INLAIN; Área de Procesamiento de Alimentos, ITA, CIA-INTA Castelar

Fecha de la defensa: 13 de noviembre de 2015

\section{Resumen}

El incremento de la proteólisis y peptidólisis a través de diversas estrategias tecnológicas, ya sea mediante operaciones simples o por la aplicación de tecnologías innovadoras, aparece como muy favorable desde el punto de vista de la aceleración de la maduración de los quesos duros, y por consiguiente, de la disminución de los costos de producción de un alimento de elevado valor agregado. El objetivo de este trabajo de tesis fue acelerar la maduración de queso Reggianito, mediante modificaciones de la tecnología tradicional, destinadas a incrementar la proteólisis y peptidólisis. Las estrategias evaluadas fueron: i) incremento de la actividad de enzimas pro- teolíticas no microbianas, la enzima coagulante residual y la plasmina, a través de una modificación de la temperatura de cocción en presencia de dos coagulantes diferentes; y ii) aplicación de la tecnología de Altas Presiones Hidrostáticas (APH). En la primera experiencia, se estudió la influencia del tipo de coagulante y de la temperatura de cocción sobre la proteólisis y la actividad de la enzima coagulante residual y de la plasmina. Se utilizaron dos temperaturas de cocción diferentes: 50 y $56^{\circ} \mathrm{C}$, y dos tipos de coagulantes: quimosina bovina y quimosina de camello. Se elaboraron quesos Reggianito miniatura y las muestras se almacenaron por 90 días a $12^{\circ} \mathrm{C}$. La temperatura de cocción influyó sobre la actividad coagulante residual, verificándose que los quesos en los cuales la misma fue de $50^{\circ} \mathrm{C}$ retuvieron una actividad significativamente mayor que los tratados a $56^{\circ} \mathrm{C}$. Por el contrario, la temperatura de cocción no modificó la actividad de la plasmina. La proteólisis primaria también resultó afectada por la temperatura de cocción. Se observó que la hidrólisis de la caseína $\alpha_{\mathrm{s} 1}$ fue menor en los quesos cuya temperatura de cocción fue de $56^{\circ} \mathrm{C}$. Además, el contenido de nitrógeno en las fracciones solubles resultó menor en los quesos tratados a $56^{\circ} \mathrm{C}$ que en los trata- 
dos a $50^{\circ} \mathrm{C}$. Se observó una influencia significativa del tipo de coagulante utilizado, especialmente en las fracciones nitrogenadas y en los perfiles peptídicos; ambos indicadores mostraron que la quimosina de camello fue levemente menos proteolítica que la quimosina bovina. Sin embargo, esas diferencias resultaron menores que las debidas a la temperatura de cocción. En la segunda experiencia, se estudió el efecto del tratamiento con APH, aplicando diferentes combinaciones presión-tiempo de mantenimiento, sobre la composición química, el pH, los recuentos microbiológicos, la proteólisis, la peptidólisis, la actividad de enzimas proteolíticas no microbianas, la textura, los parámetros cromáticos y los atributos sensoriales del queso Reggianito. Para ello, se elaboraron quesos Reggianito miniatura, a los cuales se les aplicó presiones de 100 y $400 \mathrm{MPa}$ durante 5 y $10 \mathrm{~min}$ a $20^{\circ} \mathrm{C}$ el día posterior a la elaboración. Algunos quesos no fueron tratados con $\mathrm{APH}$, los que se consideraron como controles. Todos los quesos se maduraron durante 90 días a $12^{\circ} \mathrm{C}$. Los recuentos microbiológicos fueron afectados por el tratamiento con $\mathrm{APH}$. Se verificó que los quesos tratados a 400 MPa presentaron recuentos de los microorganismos del fermento inferiores a los de los quesos controles y tratados a $100 \mathrm{MPa}$. Los quesos tratados a $400 \mathrm{MPa}$ durante 10 min exhibieron una actividad de plasmina significativamente mayor que el resto, mientras que no se observaron diferencias debidas al tratamiento con APH en la actividad coagulante residual. El seguimiento de la proteólisis mostró que los quesos tratados a $400 \mathrm{MPa}$ presentaron una mayor hidrólisis de las caseínas $\alpha_{s 1}$ y $\beta$ y niveles significativamente mayores de nitrógeno en las fracciones solubles. Los resultados del análisis de los perfiles peptídicos también mostraron una aceleración de la maduración en los quesos tratados a $400 \mathrm{MPa}$. Las muestras tratadas a $400 \mathrm{MPa}$ durante 10 min alcanzaron a los 60 días de maduración los mismos niveles de nitrógeno en las fracciones solubles y aminoácidos libres totales que las muestras control al final de la maduración (90 días). El esfuerzo y la deformación a la fractura de los quesos tratados a $400 \mathrm{MPa}$ fueron mayores que en el resto de las muestras al inicio de la maduración, mientras que esos quesos presentaron valores inferiores de elasticidad y la cohesividad durante todo el periodo de almacenamiento. Los parámetros cromáticos no resultaron afectados por el tratamiento con $\mathrm{APH}$. El panel entrenado señaló que a los 45 días de maduración, los quesos tratados a 400 MPa presentaron valores más intensos que las demás muestras en los atributos gusto salado y flavour típico.

En las dos estrategias evaluadas, se produjo un incremento en la velocidad de maduración relacionado con el incremento de la proteólisis y el incremento de la actividad de enzimas habitualmente presentes en la matriz alimentaria, como el coagulante y la plasmina. Asimismo, se obtuvieron productos de buena calidad global y no se encontraron defectos.

\section{Summary}

Technological approaches to increase proteolysis and peptidolysis in hard cheeses

The objective of this thesis was to accelerate the ripening of Reggianito cheese by means of modifications in traditional technology aimed at increasing proteolysis and peptidolysis. Two approaches were undertaken: i) increasing the activity of the no microbial proteolytic enzymes usually 
occurring in the cheese - residual coagulant enzyme and plasmin - through a modification of the curd scalding temperature in the presence of two different coagulants; and ii) application of high hydrostatic pressure (HHP). In the first experience, we tested two scalding temperature: 50 and $56^{\circ} \mathrm{C}$, and two type of coagulant enzyme, bovine or camel chymosin. The results obtained shown that a simple change in cheese making of Reggianito as decreasing the curd scalding temperature was effective to increase residual coagulant activity, with consequent acceleration of proteolysis and peptidolysis in cheeses. No advantage was obtained from replacement of bovine chymosin by camel chymosin. In the second experi- ence, we studied the effect of the HHP treatment on gross composition, $\mathrm{pH}$, microbial counts, proteolysis, peptidolysis, proteolytic activities, texture and chromatic parameters of Reggianito cheese, as well as its sensory profile. 1-day-old miniature cheeses were pressurized at 100 or $400 \mathrm{MPa}$ and $20^{\circ} \mathrm{C}$ for 5 or 10 min, while control cheeses in the trial were not pressurized. This experience provided evidence that HHP treatment at 400 MPa was effective to accelerate the ripening of Reggianito cheeses through increased proteolysis and peptidolysis. Cheeses treated at the higher pressure also showed an acceleration in the development of the sensory attributes of a ripened cheese.

\section{Metabolismo de hidratos de carbono en procariotas y eucariotas. Estudio comparativo de nucleótido-azúcar pirofosforilasas y glicosiltransferasas en bacterias y protozoos}

\author{
Ana Crsitina Ebrecht \\ anaebrecht@gmail.com \\ Director / Co-Director: Dr. Alberto A. Iglesias \\ / Dr. Sergio A. Guerrero \\ Lugar de realización: Instituto de Agrobio- \\ tecnología del Litoral. Laboratorio de Enzi- \\ mología Molecular. Facultad de Bioquímica \\ y Ciencias Biológicas. Universidad Nacional \\ del Litoral \\ Fecha de la defensa: 14 de abril de 2015
}

\section{Resumen}

En bacterias, el destino metabólico de la glucosa-1-fosfato (Glc-1P) depende principalmente de la actividad de dos nucleótido-Glc pirofosforilasas (NDP-Glc PPasas): la ADP-Glc PPasa (la cual es regulada alos- téricamente) y la UDP-Glc PPasa (que no es regulada). De esta forma, el metabolito es incorporado a la producción de glucógeno (vía ADP-Glc) o a la interconversión de la hexosa o a la producción de oligo- y polisacáridos estructurales (vía UDP-GIc).

Hemos observado que la ADP-Glc PPasa de Escherichia coli (EcoADP-Glc PPasa) exhibe cierto grado de promiscuidad hacia los sustratos y el cofactor esencial. Los resultados de este trabajo de tesis muestran que los efectores alostéricos tiene un efecto "selectivo" hacia el uso de ATP. Estos resultados plantean que el activador jugaría un papel crítico en la determinación del uso específico de ATP como sustrato. Este punto de vista de los efectores como una 
herramienta para aumentar la especificidad de la enzima abre nuevas perspectivas para la comprensión de los mecanismos de regulación alostérica y posibles procesos evolutivos de ADP-Glc PPasas, así como también para otras enzimas.

Se ha determinado que en bacterias la UDP-Glc PPasa es codificada por el gen gal $U$, aunque en enterobacterias se encontró un segundo gen, galF, que codifica una proteína que presenta elevada identidad de secuencia con GalU, pero cuya funcionalidad no es clara. En el presente trabajo de tesis se llevó a cabo la caracterización bioquímica de los productos de ambos genes. Mediante la caracterización cinética y estructural y la producción de diferentes mutantes, los resultados evidenciaron que GalU y GalF son proteínas homólogas funcionalmente activas. Sin embargo, la baja actividad de GalF nos lleva a postular que estas enzimas divergieron de un ancestro común y que por adaptaciones evolutivas las proteínas experimentaron cambios estructurales que las llevaron a cumplir diferentes roles. Este mecanismo natural podría ser una estrategia para la adquisición de propiedades reguladoras en GalF.

Por otro lado, la partición de Glc-1P en células eucariotas se produce de manera diferente a la de bacterias. Este monosacárido es utilizado principalmente por la UDPGlc PPasa para la producción de UDPGlc. Este metabolito es luego sustrato de diferentes glicosiltransferasas que la derivan a diversas vías metabólicas en la célula; por ejemplo, síntesis de oligo- y poli-sacáridos con funciones estructurales (glicosilación de proteínas y producción de glicoconjugados estructurales) o a la biosíntesis de glucógeno. La UDP-Glc PPasa no es regulada alostéricamente, por lo tanto en eucariotas heterotróficos la producción de glucógeno estaría regulada por la modulación de la actividad de la glucógeno sintasa (GSasa). Giardia lamblia es el agente etiológico de la giardiasis, una infección intestinal muy frecuente en los niños. La investigación sobre este protozoo es impulsada tanto por su impacto en la salud pública como su relevancia evolutiva, ya que se ubica en la rama divergente más tempranamente del linaje eucariota. Se sabe que la Glc es una fuente de energía clave en el metabolismo del organismo y este monosacárido es acumulado en forma de glucógeno en los trofozoítos del parásito. La síntesis de glucógeno y de oligo- y polisacáridos estructurales es crítica para la supervivencia y la patogenicidad del parásito. Sin embargo la caracterización de las enzimas implicadas en estas vías está lejos de ser completa. En este trabajo de tesis, presentamos el clonado molecular de los genes que codifican para la GSasa y la UDP-Glc PPasa de G. lamblia (GlaGSasa y GlaUDPGlc PPasa, respectivamente), seguido de sus expresiones heterólogas en E. coli, purificación y caracterización bioquímica.

En su conjunto, los resultados sugieren que en este parásito la UDP-Glc PPasa es regulada mediante un mecanismo post-traduccional de tipo redox; además, presenta propiedades distintivas a las UDP-Glc PPasas de otros protozoos previamente estudiados, ya que la enzima exhibe la capacidad de sintetizar UDP-Glc y UDP-Gal y de utilizar TTP como sustrato alternativo al UTP. De esta forma, jugaría un papel clave proporcionando sustratos a las glicosiltransferasas para la producción de oligo- y polisacáridos claves para la supervivencia y diferenciación de las células. 
Hasta el momento no se ha informado la caracterización de ninguna GSasa de protozoos, siendo la enzima de G. lamblia la primera en ser expresada en forma recombinante y caracterizada cinéticamente. La enzima del parásito se ubica dentro de la familia de las GSasas eucariotas, pero exhibe propiedades intermedias entre las proteínas de bacterias y de organismos eucariotas, lo cual la hace única entre todas las GSasas caracterizadas hasta el momento.

Con todo, los resultados de este trabajo de tesis proporcionan un aporte novedoso al entendimiento del metabolismo de la síntesis de carbohidratos con funciones relevantes en bacterias y protozoos, así como a la relación estructura-función, -regulación y evolución de las enzimas implicadas en el mismo.

\section{Summary}

Carbohydrates metabolism in prokaryotes and eukaryotes. A comparative study of sugar-nucleotide pyrophosphorylases and glycosyltranferases in bacteria and protozoa.

The characterization of the nucleosidediphospho-glucose pyrophosphorylase (NDP-
Glc PPases) and glicolsiltransferases is relevant to understand the metabolism (and regulation) of carbohydrates in the respective organism and their functional derivations. This thesis is based on the characterization of NDP-sugar PPases and glycosyltransferases (specifically glycogen synthase, GSase) from Gram-positive bacteria and protozoa, as well as a comparative analysis of the properties of enzymes according to their origin and those equivalent proteins found in other organisms. The study of the relationships between protein structure, function and regulation seek to achieve a better understanding of the kinetic mechanisms of NDP-sugar PPases and GSase at enzymatic level. This would allow a deeper knowledge at metabolic level on how the Glc-1-phosphate can be split in different metabolisms and this process is regulated in different cells. As a general strategy, the genes coding for the respective enzymes were cloned for the production of recombinant proteins, and the purification to a high degree. The purified enzymes were characterized in their kinetic, regulatory and structural properties.

\section{Impacto de los ácidos grasos isoméricos trans y CLA sobre la modulación lipídica en ratas alimentadas con dietas enriquecidas o deprivadas en ácido linoleico}

\section{Ana Clara Fariña}

afarina@fbcb.unl.edu.ar

Director de Tesis: Dr. Claudio A. Bernal

Co-director de Tesis: Dra. Marcela A. González

Cátedra de Bromatología y Nutrición -

Departamento de Ciencias Biológicas.

Facultad de Bioquímica y Ciencias Biológi-

cas. Universidad Nacional del Litoral

17 de Abril de 2015

\section{Resumen}

Ha sido demostrado que diferentes tipos de grasas dietarias están implicadas en el desarrollo y/o prevención de enfermedades crónicas no transmisibles (ECNT). Uno de los problemas nutricionales actuales, fundamentalmente en los países occidentales, está relacionado al consumo excesivo de aceites ricos en ácidos grasos (AG) de 
la serie n-6. Esto ha conducido a dietas con relaciones de $A G$ n-6/n-3 muy por encima de las recomendadas. También, y con menor frecuencia, coexisten grupos poblacionales con déficits nutricionales asociados a deprivación de los AG esenciales: ácido linoleico $(A L)$ y ácido $\alpha$-linolénico. Por otra parte, durante las últimas décadas, los isómeros de AG han despertado un gran interés por sus potenciales efectos sobre la salud humana. Así, los AG-trans (AGT) de origen industrial han sido asociados a efectos deletéreos incrementando el riesgo de enfermedades cardiovasculares, inflamación aguda, diabetes, entre otras ECNT. Mientras que, los conjugados del ácido linoleico (CLA) han mostrado poseer propiedades funcionales, denotando un horizonte promisorio para la prevención de ciertas ECNT. Al mismo tiempo, dependiendo de numerosos factores, estos AG isoméricos pueden tener efectos negativos sobre la salud.

El impacto metabólico de los isómeros AGT o CLA, está relacionado a numerosos factores, entre ellos: tipo específico de isómero considerado, tiempo y dosis de tratamiento, especie, modelo experimental, como también al entorno nutricional existente. En virtud de esto, la hipótesis de la presente tesis fue: "los isómeros AGT y CLA poseen un efecto diferencial sobre la modulación del metabolismo lipídico y glucídico dependiendo del entorno nutricional generado por los niveles dietarios de AL". El objetivo de este trabajo fue investigar los potenciales efectos metabólico-nutricionales de los AGT y los CLA en dietas enriquecidas o deprivadas en $\mathrm{AL}$ en un modelo experimental animal.

Ratas macho, jóvenes, de la cepa Wistar fueron alimentadas durante 60 días con alguna de las siguientes dietas experimentales: ${ }^{+} A L$ : enriquecida en $A L$; $-A L$ : deprivada de $A L ;+{ }^{+} A L+A G T: ~+A L$ sustituída con aceite rico en AGT; - $A L+A G T$ : - $A L$ sustituída con aceite rico en $A G T ;{ }^{+} A L+C L A:{ }^{+} A L$ sustituída con aceite rico en CLA; -AL+CLA: -AL sustituída con aceite rico en CLA. Las sustituciones de aceites permitieron arribar al 1\% (p/p) del isómero correspondiente a cada dieta. En aspectos nutricionales, principalmente se evaluó la ganancia de peso, eficiencias dietarias y cambios en la composición corporal. En el metabolismo lipídico, fundamentalmente se puntualizó en la retención de isómeros de $A G$, los perfiles de lípidos séricos y tisulares, como también en mecanismos de regulación de triglicéridos (TG); y en el metabolismo de la glucosa, se estudiaron la captación, incorporación y oxidación de la misma, y la síntesis de glucógeno en músculo soleo aislado.

En resumen, a partir de los resultados más relevantes hallados, puede concluirse que:

- Los AGT, a niveles equivalentes de los que podrían ser consumidos por la población humana, producen efectos deletéreos sobre animales de experimentación, fundamentalmente incrementando la acreción de lípidos en hígado y tejido adiposo.

- La deprivación de AL genera cambios en el entorno metabólico de los animales influyendo tanto sobre el efecto de los AGT, como en los mecanismos de acción de éstos.

- Los niveles de 11t-18:1, como asimismo su bioconversión a 9c,11tCLA podrían estar atenuando los efectos deletéreos reportados por diversos investigadores para aceites enriquecidos en 9t-18:1.

- Los CLA poseen efectos metabólicos diferentes en función del status de $A L$.

- A bajos niveles de ingesta de AL es posible una alta interacción con los CLA conduciendo a ciertos efectos biológicos benéficos, como: reducción de la acreción 
grasa, reducción de los TG circulantes, incremento en la biosíntesis de AG poliinsaturados (AGPI) de cadena larga (AGPI-CL) n-3 asociado a una reducción de la biosíntesis de AGPI-CL n-6 y mejoramiento de la utilización de la glucosa.

- Los CLA en dieta deprivada de AL conducen en la rata a modificaciones metabólicas atenuadas de aquellas descriptas en el ratón.

Es factible postular que la baja ingesta de $\mathrm{AL}$ podría generar en las ratas una mayor sensibilidad a los CLA, o bien, que en dietas muy ricas en AL, Ios CLA no compitan en la metabolización de los AGPI n-6, conduciendo a efectos diferenciales en ambas situaciones metabólicas. Esto no descarta la posibilidad que diferentes niveles de metabolitos bioactivos se puedan generar a partir de los CLA consumidos.

\section{Abstract}

Impact of trans and CLA isomeric fatty acids in metabolic modulation in rats fed linoleic acid enriched or deprived diets

Nowadays, an important nutritional problem is related to the excessive consumption of oils rich in n-6 fatty acids (FA). This unbalance coexists with nutritional deficits associated to deprivation of essential FA. Moreover, FA isomers have aroused great interest for its potential effects on human health. Thus, the trans-FA (TFA) from industrial origin have been associated with deleterious effects. Otherwise, conjugated linoleic acid (CLA) has shown to possess functional, as well as, negative properties on health.

The aim of this study was to investigate the potential metabolic-nutritional effects of TFA and CLA in LA-enriched or deprived diets in an experimental animal model.

Male young Wistar rats were fed for 60 days with one of the following experimental diets: ${ }^{+} L A$ : enriched with LA; 'LA: deprived of $L A ;+{ }^{+} L A+T F A:+$ LA substituted with oil rich in TFA; -LA+TFA: -LA substituted with oil rich in TFA; + $L A+C L A:{ }^{+} L A$ substituted with oil rich in CLA; -LA+CLA: -LA substituted with oil rich in CLA. Nutritional aspects, as well as, lipid and glucose metabolisms were evaluated.

It can be concluded that:

- TFA produce deleterious effects mainly through increasing the accretion of lipids.

- LA deprivation influences both, the effect of TFA and their mechanisms of action.

- Low intake of LA could result in an increased sensitivity to the CLA.

In LA rich diets, CLA would not compete in the metabolism of $n-6$ polyunsaturated $F A$, leading to differential effects in both metabolic situations. Moreover, different levels of bioactive metabolites could be generated from the CLA consumed.

\section{Desarrollo de alimentos funcionales a partir de lino oleaginoso (Linum usitatissimum L.)}

\section{Maricel Andrea Gallardo}

Gallardo.maricel@inta.gob.ar

Director: Rolando José González

Lugar de realización: INTA EEA Paraná- ITA

- FIQ (UNL) (Santa Fe). Grupo de gené- tica, mejoramiento y biotecnología vegetal (INTA), Laboratorio de Cereales y Oleaginosas (ITA)

Fecha de la defensa: 24/11/15 


\section{Resumen}

El lino es una oleaginosa invernal, el cual posee un alto contenido de ácido linolénico (Omega-3). Las semillas de lino tienen efectos beneficiosos en la prevención y/o tratamiento del cáncer y la enfermedad cardiovascular.

El objetivo general de la tesis fue desarrollar un alimento funcional a partir de lino (Linum usitatissimum L.) oleaginoso que responda a las necesidades nutricionales y alimentarias de la población, con más ventajas que los productos actuales.

A través de la caracterización de la composición química de siete cultivares de lino sembrados en dos fechas diferentes y de la determinación de las variables químicas que fueron afectadas por el cultivar y/o la fecha de siembra, se seleccionó un cultivar de origen nacional, que presentó un buen perfil de ácidos grasos y un alto contenido de Fe y se desarrolló un alimento funcional con harina lino. A través de un estudio de estabilidad, se determinó que la alteración producida durante el almacenamiento (tanto por el olor como por la aparición de sabores desagradables) fue directamente proporcional al tiempo de estudio transcurrido (90 días) en todas sus temperaturas de almacenamiento; que las galletitas con lino pueden ser conservadas a temperaturas de 5 y $15^{\circ} \mathrm{C}$, sin que sus características sensoriales se deterioren en un período menor a 30 días de almacenamiento; que es necesario realizar la estimación de la vida útil de alimentos elaborados con lino, para cada formulación , y además, que se debe prever la utilización de envases protectores que atenúen la oxidación lipídica.

\section{Summary}

Development of functional foods from flaxseed (Linum usitatissimum I.)

Flax is a winter oilseed, which has a high content of linolenic acid (Omega-3). Flax seeds have beneficial effects in the prevention and / or treatment of cancer and cardiovascular disease.

The overall aim of the thesis was to develop a functional food from flaxseed (Linum usitatissimum L.) that meets the nutritional and dietary needs of the population, with more advantages than current products.

Through the characterization of the chemical composition seven cultivars of flax, seeded on two different dates, and determination of chemical variables that were affected by the cultivar and/or seeding date, it was selected cultivar of national origin, which it presented a good profile of fatty acids and a high content of $\mathrm{Fe}$ and developed a functional food with flax flour. Through a stability study, it was determined that the alteration produced during storage (by both the odor and the appearance of unpleasant flavors) was directly proportional to the time elapsed study (90 days) in all storage temperatures; the cookies with flax can be stored at temperatures of 5 and $15^{\circ} \mathrm{C}$, without their sensory characteristics deteriorate in less than 30 days of storage period; it is necessary to estimate the shelf life of foods made from flaxseed, for each formulation, and also which should include the use of protective packaging that attenuate lipid oxidation. 


\section{Estudios funcionales de metalochaperonas de cobre involucradas en la biogénesis mitocondrial}

\section{Lucila Garcia}

lucilagarciasf@gmail.com

Director/ Co-Director: Dr. Daniel Hugo González / Dra. Elina Welchen

Lugar de realización: Instituto de Agrobiotecnolgía del Litoral (IAL). Laboratorio de Biología Molecular y Celular. Facultad de Bioquímica y Ciencias Biológicas. Universidad Nacional del Litoral

Fecha de la defensa: 5 de Junio de 2015

\section{Resumen}

El Complejo IV o citocromo c oxidasa (COX) es la enzima terminal de la cadena transportadora de electrones de la mitocondria. El ensamblaje de COX requiere la participación de numerosas proteínas codificadas en el genoma nuclear y tres proteínas estructurales (COX1, COX2 y COX3) codificadas en el genoma mitocondrial. Durante el ensamblado del Complejo IV debe ocurrir la formación de centros metálicos de cobre y hierro hémico en COX1 y COX2, necesarios para la actividad del complejo. La búsqueda de homólogos de las proteínas de levaduras y mamíferos ha permitido encontrar proteínas involucradas en el ensamblado del Complejo IV en Arabidopsis thaliana (Arabidopsis). Entre las proteínas identificadas figuran supuestos homólogos de OXA1, COX10, COX11, COX15, COX17, COX19, COX23 y SC01. COX17, COX19 y COX23 que participarían en la distribución del cobre para su inserción en COX mediada por SCO1 y COX11. Este grupo de proteínas comparte dominios de cisteínas involucrados en la unión y trans- ferencia del metal. El modelo propuesto en levaduras sugiere que COX17 transfiere el cobre a SCO1 y a COX11 y éstas lo transportan a COX2 y COX1, respectivamente. El rol de COX19 y COX23 aún no ha sido dilucidado. En Arabidopsis encontramos dos genes que codifican proteínas homólogas a COX17, denominados AtCOX17-1 y AtCOX17-2, y dos genes AtCOX19 que codifican proteínas idénticas. Tanto AtCOX17-1 y AtCOX17-2 como AtCOX19 son capaces de complementar a las respectivas mutantes nulas de levaduras, lo que sugiere que las proteínas de Arabidopsis participan en la biogénesis de COX. Curiosamente, los promotores de AtCOX17-1, AtCOX17-2 y AtCOX19 son inducidos en distintas situaciones que generan estrés oxidativo en plantas. En este trabajo de Tesis nos propusimos estudiar la función de las metalochaperonas de cobre AtCOX17 y AtCOX19. Para cumplir con este objetivo general, estudiamos la localización subcelular de estas proteínas y obtuvimos plantas con niveles alterados de las mismas. Estudios de microscopía confocal en plantas indicaron que ambas proteínas tienen localización mitocondrial. La localización mitocondrial de estas proteínas está de acuerdo con la función propuesta en la biogénesis de COX. Por otra parte, la disminución de los niveles de expresión de AtCOX17-1 y AtCOX17-2 en forma simultánea retrasa el crecimiento en Arabidopsis. El fenotipo observado podría deberse a una deficiencia en la actividad del Complejo IV. Además, la disminución de la expresión de cada uno 
de los genes AtCOX17 en forma individual no afecta el desarrollo de las plantas. Esto es coincidente con el hecho de que dichas plantas no presentan diferencias en la actividad COX ni en la respiración respecto de plantas salvajes. Estos resultados sugieren la existencia de redundancia funcional entre AtCOX17-1 y AtCOX17-2 en la biogénesis del Complejo IV. Sin embargo, la disminución de la expresión de los genes AtCOX17 de manera individual genera plantas cuya respuesta frente a estrés se encuentra alterada, ya que presentan una menor inducción de genes de respuesta a estrés y mayores niveles de anión superóxido y lípidos peroxidados luego de un tratamiento con $\mathrm{NaCl}$. Por el contrario, plantas con mayores niveles de AtCOX17-1 presentan menores niveles de lípidos peroxidados y mayor diámetro de roseta luego del tratamiento con $\mathrm{NaCl}$. En conjunto, estos resultados indican que las proteínas AtCOX17 serían necesarias para que ocurra una respuesta eficiente a estrés en plantas. También se estudió la homeostasis de cobre en plantas con niveles alterados de AtCOX17 o de AtCOX19. Los resultados obtenidos sugieren que AtCOX17-2 y AtCOX19 podrían estar involucradas en el transporte y/o la distribución del metal en Arabidopsis, mientras que la modificación de los niveles de AtCOX17-1 no produciría cambios en la homeostasis de cobre. Los resultados obtenidos indican funciones diferenciales para las metalochaperonas de cobre AtCOX17 y AtCOX19. Particularmente, las proteínas AtCOX17 participan en la respuesta a estrés, mientras que AtCOX17-2 y AtCOX19 participan en la homeostasis de cobre y/o hierro. Si estas funciones están relacionadas con la participación de estas proteí- nas en la biogénesis del Complejo IV o son funciones adicionales adquiridas en plantas durante la evolución son interrogantes abiertos para futuras investigaciones.

\section{Summary}

Functional studies of copper metalochaperons involved in mitochondriall biogenesis.

Plant mitochondria contain four complexes involved in electron transport, one complex responsible for ATP synthesis and two plant-specific alternative respiratory pathways. Complex IV or cytochrome $c$ oxidase (COX) is the terminal enzyme of the mitochondrial electron transport chain and is involved in the conversion of oxygen to water. COX is composed of subunits encoded either in the mitochondrial or the nuclear genome. The three core subunits (COX1, COX2 and COX3) are encoded in the mitochondrial genome and are present in COX from different organisms, whilst the number of subunits encoded in the nucleus is variable. In addition to structural subunits, several proteins involved in COX assembly have been identified. During COX assembly, copper and heme a must be inserted into the core subunits since they form the catalytic centers necessary for proper COX activity. Copper delivery was thoroughly studied in mammals and yeast. A simple model proposes that copper is transferred from COX17 to SCO1 and COX11, which in turn transfer copper to COX2 and COX1, respectively. COX17 is a soluble protein from the mitochondrial intermembrane space (IMS) that contains four cysteines arranged in two $\mathrm{CX}_{9} \mathrm{C}$ motifs and two additional cysteines involved in copper coordination. Another protein from the IMS, COX19, also conta- 
ins $\mathrm{CX}_{9} \mathrm{C}$ motifs and is involved in copper delivery in yeast. Homologues of COX17 and COX19 are encoded in plant genomes. In Arabidopsis thaliana (Arabidopsis), two different genes, AtCOX17-1 and AtCOX172 , encode proteins which are able to complement the respiratory deficiency of a yeast cox17 null mutant. Moreover, the expression of AtCOX17 genes is induced under biotic and abiotic stress conditions. Similar to AtCOX17 genes, AtCOX19 genes (AtCOX19-1 and AtCOX19-2), which encode identical proteins, are able to complement a yeast cox19 null mutant and are induced under stress conditions.

In this work, we focused on the function of AtCOX17 and AtCOX19 in Arabidopsis. First, we determined the subcellular location of AtCOX17-1 and AtCOX19 using confocal microscopy. Our studies showed that both proteins are located in mitochondria, which is in agreement with their function in COX biogenesis. We also analyzed plants with reduced levels of AtCOX17 or AtCOX19. Silencing of both AtCOX17 genes originated only a limited number of lines which were strongly affected in growth. This phenotype may be explained by the role of AtCOX17 in COX assembly. This is in agreement with previous studies which indicated that knockout mutations in genes encoding proteins involved in COX assembly cause an arrest in embryo development. On the contrary, silencing of single AtCOX17 genes did not significantly affect plant growth or COX acti- vity suggesting the existence of functional redundancy. However, plants with reduced expression of individual AtCOX17 genes showed a reduced or delayed response to stress, since they were unable to properly induce a set of stress-responsive genes and contained higher ROS and lipid peroxidation levels after a salt stress treatment. These results indicate that AtCOX17 genes have acquired functions related to stress responses. In fact, plants with reduced expression of both AtCOX17 genes showed a general decrease in the expression of genes that participate in the response to many different types of stress even under basal conditions. We also studied the role of AtCOX17 and AtCOx19 in copper homeostasis. Silencing the expression of either AtCOX17 gene or AtCOX19 did not modify the expression of genes involved in copper transport or delivery. However, plants with increased expression of AtCOX19 or AtCOX17-2 showed a significant increase in the expression of genes involved in responses to copper limitation. Although AtCOX17 and AtCOX19 show structural similarity, have the same subcellular localization and are induced under similar situations, they probably have different functions in plants. Our results suggest that AtCOX17 genes are involved in stress responses while AtCOX19 participates in modulating metal homeostasis. The link between these functions and their role in COX biogenesis is an open question for future studies. 


\section{Modificaciones producidas por metales pesados sobre los parámetros fisiológicos y el sistema detoxificante de la macrófita Eichhornia crassipes que crece en humedales construidos para tratamiento de efluentes}

\section{César Iván González}

biocesarivan@gmail.com

Director: Dra. María Alejandra Maine

Co-Director: Dra. Jimena Cazenave

Lugar de realización: Cátedra de Química

Analítica. Facultad de Ingeniería Química.

Universidad Nacional del Litoral

Fecha de la defensa: 16 de septiembre de 2015

\section{Resumenn}

En esta tesis se evaluó si metales pesados (Cr (III), Ni (II) y Zn (II)), en forma aislada y combinada, tanto en ausencia como en presencia de nutrientes (fósforo $(P)$ y nitrógeno $(\mathrm{N})$ ), provocan modificaciones sobre parámetros fisiológicos y de estrés oxidativo, en la planta acuática Eichhornia crassipes que crece en humedales construidos para tratamiento de efluentes. En primer lugar, se expuso E. crassipes, en corto tiempo, a la presencia de los tres metales en forma aislada. Dicha exposición produjo cambios fisiológicos favorables que demostrarían una continuidad en la actividad fotosintética de la planta, mostrando también un incremento en la respuesta de su defensa enzimática antioxidante. En segundo lugar, se expuso E. crassipes a metales pesados en combinación con nutrientes ( $P$ y N). Los resultados mostraron una influencia negativa sobre la sorción de los metales al agregar nutrientes y un aumento de las actividades enzimáticas antioxidantes. Por último,
E. crassipes fue expuesta a metales pesados en forma combinada, con el agregado de nutrientes (P y N).Se observó, en presencia como en ausencia de nutrientes, cambios fisiológicos favorables y un aumento de las actividades de las enzimas antioxidantes, cuando en las combinaciones de metales estaba presente el Zn. La presencia de Zn produjo una mejor respuesta de la planta a los metales, activando el sistema de defensa antioxidante. E. crassipes demostró alta plasticidad, incrementando la actividad de sus enzimas antioxidantes en respuesta a los metales pesados y sus efectos de stress oxidativo.

\section{Summary}

Changes produced by heavy metals on physiological parameters and detoxification system of macrophyte Eichhornia crassipes growing in constructed wetlands for wastewater treatment.

In this thesis there was evaluated if heavy metals (Cr (III), Ni (II) and Zn (II)), in isolated and combined form, both in absence and in presence of nutrients (phosphorus $(P)$ and nitrogen $(\mathrm{N})$ ), provoke modifications on physiological parameters and oxidative stress, in the aquatic plant Eichhornia crassipes that grows in wetlands constructed for treatment of effluents. First, E. crassipes was exposed, in short time, to the presence of three metals in isolated form. The exhibition produced favorable 
physiological changes that would demonstrate continuity in the photosynthetic activity of the plant, showing also an increase in the response of his enzymatic antioxidant defense. Secondly, E. crassipes was exposed to heavy metals in combination with nutrients ( $\mathrm{P}$ and $\mathrm{N}$ ). The results showed a negative influence on metal sorption to added nutrients and an increase on antioxidant enzyme activities. Finally, E. crassipes was exposed to heavy metals in combined form, with the addition of nutri- ents ( $\mathrm{P}$ and $\mathrm{N}$ ). It was observed in presence and absence of nutrients, favorable physiological changes and an increase in antioxidant enzymes activities, when Zn was present in metal combinations. Zn produced a better plant response to the studied metals, activating antioxidant defense system. E. crassipes demonstrated high plasticity, increasing activities of its antioxidant enzymes to response to heavy metals and oxidative stress effects.

\section{Diseño, síntesis y aplicaciones de nuevas estructuras peptídicas con actividad antimicrobiana}

\section{María Verónica Húmpola}

mvhumpola@hotmail.com

Directora: Dr. Georgina Tonarelli

Co-Director: Dr. Arturo Simonetta

Dto. Química Orgánica (FBCB) y Cátedras de Microbiología y Biotecnología del Dto. de Ing. en Alimentos (FIQ.) Facultad de Bioquímica y Ciencias Biológicas (FBCB) y Facultad de Ingeniería Química (FIQ). Universidad Nacional del Litoral.

Fecha de la defensa: 06-03-2015

\section{Resumen}

Los péptidos antimicrobianos (PAs) forman parte del sistema inmune no específico de muchos organismos superiores. Las bacterias son sensibles a la acción de los PAs debido a que estas moléculas son catiónicas y su blanco de acción son las membranas bacterianas, que contienen una alta proporción de fosfolípidos aniónicos. El objetivo de esta Tesis ha sido diseñar y sintetizar nuevas estructuras peptídicas antimicrobianas sobre la base de la secuencia de la bacteriocina Plantaricina 149 (YSLQMGATAIKQVKKLFKKKGG, PIn 149), así como estudiar las propiedades fisicoquímicas, biológicas y terapéuticas de estas nuevas moléculas, a fin de evaluar su utilización como fármacos y como conservantes alimentarios. Se sintetizaron, empleando la química Fmoc en fase sólida, cuatro análogos que cubren la región 7-19 de PIn 149, denominados A1 (región 7-17), A2 (región 10-19), A3 (región 14-19) y A4 (región 15-18), y dos oligómeros lineales de la secuencia KLFK (A4), denominados DA4 (KLFK) ${ }_{2}$ y TA4 (KLFK) $)_{3}$. Los péptidos A1, A2, DA4 y TA4 presentaron buena actividad antimicrobiana frente a bacterias Gram (+) y Gram (-) (CIM= 2,6 a 60,9 $\mu \mathrm{M})$, mientras que DA4 y TA4 presentaron moderada actividad frente a levaduras. La actividad hemolítica de la mayoría de los péptidos frente a eritrocitos humanos fue baja. El péptido TA4 presentó los mejores índices terapéuticos (ITps= 130 y 14,7, frente a bacterias y levaduras, respectivamente). 
Con el fin de mejorar las propiedades antimicrobianas, los péptidos se conjugaron con ácidos grasos saturados e insaturados de diferente longitud de cadena hidrocarbonada (C8:0 a C20:0). En la mayoría de los casos, la acilación resultó beneficiosa para incrementar la actividad antimicrobiana. Los lipopéptidos de A2 fueron los más activos frente a bacterias Gram (+) y Gram (-) $(\mathrm{CIM}=0,7$ a $20,7 \mu \mathrm{M})$, mientras que DA4 conjugado con ácido octanoico fue el más activo frente a levaduras (C8:0-DA4: CIM= 13,6 $\mu \mathrm{M})$. Por otra parte, la conjugación con ácidos grasos provocó un aumento en la actividad hemolítica, lo que se correlacionó con un incremento de la hidrofobicidad. A fin de mejorar las propiedades terapéuticas de los análogos más activos se diseñaron y sintetizaron análogos de sustitución de A2, TA4 y de A2 conjugado con ácido decanoico (C10:0-A2). Para ello se utilizaron aminoácidos no naturales tales como ornitina, D-aminoácidos, N-metil aminoácidos y aminoácidos fluorados. Los análogos de sustitución de C10:0-A2 y TA4 con $\mathrm{N}$-metil aminoácidos presentaron buena actividad inhibitoria frente a bacterias Gram (+) y Gram (-), y moderada actividad frente a levaduras. Además, la incorporación de $\mathrm{N}$-metil aminoácidos disminuyó significativamente la actividad hemolítica de estos péptidos. Por otra parte, la sustitución con D-aminoácidos causó, en la mayoría de los casos, una disminución de las actividades antimicrobiana y hemolítica de los análogos conjugados. La estabilidad enzimática de los péptidos y lipopéptidos sustituidos fue evaluada frente a tripsina, quimotripsina y enzimas séricas. Los resultados demostraron que la sustitución con D-aminoácidos fue eficaz para aumentar la estabilidad frente a todas las enzimas. Estos resultados demuestran que la sustitución con N-metil aminoácidos y D-aminoácidos son buenas estrategias para mejorar las limitaciones que presentan estos compuestos para ser utilizados como fármacos de uso sistémico. El conjunto de los resultados obtenidos en esta Tesis evidencian el potencial que poseen estos péptidos y lipopéptidos antimicrobianos para ser utilizados como fármacos o para ser aplicados en sistemas de conservación de alimentos, ya que se ha demostrado que presentan muy buenas propiedades antimicrobianas frente a un amplio espectro de bacterias Gram (+) y Gram (-) y frente a levaduras.

\section{Summary}

Design, synthesis and applications of new peptide structures with antimicrobial activity.

Antimicrobial peptides (PAs) are part of the non-specific immune system of many higher organisms. Bacteria are sensitive to the action of PAs as these molecules are positively charged and their target of action is the bacterial membrane, which contain a high proportion of anionic phospholipids. The aim of this Thesis was to design and synthesize new antimicrobial peptide structures based on the sequence of the bacteriocin Plantaricin 149 (YSLQMGATAIKQVKKLFKKKGG, PIn 149), and to study their physicochemical, biological and therapeutic properties in order to evaluate their potential therapeutic and technological applications. The results of this Thesis as a whole have shown that many of the synthesized oligomers and lipopeptides have excellent antimicrobial properties against a broad spectrum of Gram (+) and Gram (-) bacteria and yeasts. In this sense, the most promising antibacterial compounds were the lipopeptides of A2 (IKQVKKLFKK, 10 -19 
region of PIn 149) conjugated with saturated and unsaturated fatty acids $(\mathrm{MIC}=0.7 \mathrm{a}$ $20.7 \mu \mathrm{M})$, and the most interesting antifungal compound was the lipopeptide of DA4 $\left[(\mathrm{KLFK})_{2}, 15\right.$ - 18 region of PIn 149] conjugated with octanoic acid ( $\mathrm{MIC}=13.6 \mu \mathrm{M})$.
Also, the results obtained with peptides containing $\mathrm{N}$-methyl and D-amino acids suggest that the substitution with these unnatural amino acids is a good strategy to overcome some of the limitations of the peptides in the design of new drugs.

\section{Incorporación de ácidos grasos trans y CLA dietarios en lípidos tisulares y su potencial implicancia metabólica en animales de experimentación}

\section{Paola G. Illesca}

pillesca@fbcb.unl.edu.ar

Director: Dr. Claudio A. Bernal

Lugar de realización: Cátedra de Bromatología y Nutrición. Departamento de Ciencias Biológicas. Facultad de Bioquímica y Ciencias Biológicas. Universidad Nacional del Litoral

Fecha de defensa: 17 de diciembre de 2015

\section{Resumen}

Numerosos estudios han relacionado la cantidad y calidad de la grasa dietaria con factores de riesgo asociados al desarrollo de enfermedades crónicas no transmisibles (ECNT). El consumo elevado de grasas con una desbalanceada relación de ácidos grasos (AG) n-6/n-3, como así también de grasas ricas en isómeros de $A G$ trans (AGT) y Conjugados del Ácido Linoleico (CLA), han mostrado ejercer un impacto diferencial en el desarrollo/progresión de las ECNT. Alteraciones bioquímico-metabólicas reportadas en humanos y modelos experimentales animales han sido asociadas a dietas ricas en AGT de origen industrial con alto contenido de ácido elaídico (9t-18:1). No obstante, se han observado efectos beneficiosos de algunos AGT dietarios de origen natural presentes en carne y lácteos derivados de rumiantes, como el ácido trans vaccénico (VA, 11t-18:1) y ácido ruménico (RA). Aunque los mecanismos de acción subyacentes no han sido completamente dilucidados, el impacto metabólico ha mostrado ser dependiente de los niveles de isómeros específicos alcanzados en tejidos. Además, su metabolismo estaría modulado por Ios tipos de AG que componen la dieta y la cantidad relativa de los isómeros.

Los efectos de un moderado o bajo contenido de AGT o CLA sobre el metabolismo lipídico en dietas de niveles recomendados o elevados de grasa son muy poco conocidos. Por lo tanto, el objetivo del presente trabajo de tesis fue investigar los potenciales efectos de AGT y CLA sobre aspectos bioquímicos y nutricionales en un modelo experimental animal a niveles recomendados o elevados de grasa dietaria, caracterizada por una elevada relación de AG n-6/ n-3 y contenido de isómeros factible de ser consumido por la población.

Para alcanzar el objetivo propuesto, ratas macho jóvenes de la cepa Wistar, luego del destete, fueron alimentadas durante 30 días con alguna de las siguientes dietas experimentales, producto de la combinación de 
dos variables: a) nivel de grasa dietaria (7\% o 20\%) y b) la sustitución parcial de la grasa dietaria ( $1 \%$ o 2,86\%) con aceite rico en isómeros de AG (AGT o CLA). Las dietas conformadas fueron: C7, dieta control; AGT7, dieta a niveles recomendados de grasa parcialmente sustituida con AGT; CLA7, dieta a niveles recomendados de grasa parcialmente sustituida con CLA; C20, dieta control con elevados niveles de grasa; AGT20, dieta de elevado nivel de grasa parcialmente sustituida con AGT; CLA20, dieta de elevado nivel de grasa parcialmente sustituida con CLA. En dichos animales se evaluaron parámetros nutricionales: ganancia de peso, eficiencia energética de las dietas, composición y retención energética corporal; y relacionados al metabolismo lipídico, enfatizando en la incorporación/retención de isómeros de $A G$ en diferentes tejidos, suero y secreciones, mecanismos de regulación de los triacilglicéridos (TAG), actividades y expresión de enzimas y expresión de factores de transcripción involucrados en la síntesis y oxidación de AG.

Respecto de los más destacables resultados obtenidos, se pudo concluir lo siguiente: 1) Los isómeros de AGT y CLA fueron incorporados y retenidos de manera diferencial en tejidos, suero y secreciones según el tipo de isómero; observándose dependencia del nivel de grasa dietaria. 2) AGT y CLA modificaron la biosíntesis de LCPUFA de manera diferencial según el contenido de grasa en la dieta.3) La bioconversión de VA a RA en hígado y tejido adiposo de animales alimentados con AGT fue menor a elevados niveles de grasa. 4) $\mathrm{La}$ ingesta moderada de AGT conteniendo VA, no acrecentó la ganancia de peso corporal, ni los depósitos grasos, ya aumentados por la ingesta de dieta rica en grasa. 5) El efecto de los AGT y CLA sobre el metabolismo lipídico estuvo asociado principalmente al nivel de grasa de la dieta, observándose mayores alteraciones por la ingesta de isómeros a niveles recomendados de grasa.

La sustitución parcial de la grasa en dietas desbalanceadas en PUFA por aceites ricos en isómeros AGT o CLA, modifica de manera diferente parámetros nutricionales y metabólicos en rata, dependiendo del contenido de grasa de la dieta. De esta manera, los resultados del presente trabajo de tesis contribuyen a ampliar el conocimiento sobre las implicancias metabólicas del consumo de isómeros de $A G$ dietarios a niveles de ingesta alcanzables por la población. Asimismo, se espera que sean de utilidad para comprender la implicancia de la composición y cantidad de grasa ingerida en el desarrollo de las ECNT y permita tomar decisiones tendientes a disminuir su incidencia.

\section{Summary}

Incorporation of dietary trans fatty acids and CLA into the tissue lipids and their potential metabolic implications in experimental animals.

The amount and type of dietary fats have been linked with chronic noncommunicable diseases (NCD). High intake of fat with an unbalance of n-6/n-3 fatty acid (FA) ratio and fats enriched with trans-FA (TFA) or Conjugates of linoleic acid (CLA) showed a differential deleterious on NCD risk. The metabolic alterations have been associated with industrial TFA rich in elaidic acid (9c-18:1). However, some beneficial effects have been observed in naturally occurring dietary TFA: trans-vaccenic acid (11t-18: 1) and rumenic acid (RA). The metabolic impact has shown to be dependent on the levels of specific isomers achieved in tissues and of the com- 
position of FA in the diet. The aim of this thesis was to investigate the effects of TFA and CLA on biochemical and nutritional parameters in rats fed with high or recommended dietary fat levels. We conclude: 1) the TFA and CLA isomers tissue retention was depending on the type of isomer and dietary fat level, 2) the supplementation with TFA or CLA, and the amount of dietary fat modified the LC-PUFA biosynthesis in a dif- ferent manner, 3) the bioconversion of VA to RA in the liver of animals fed TFA was lower at high fat levels. 4) the body weight gain and fat depots at high fat levels increased significantly, but did not change by a moderated consumption of TFA or CLA, and 5) the effect of TFA and CLA isomers on lipid metabolism was associated with dietary fat level showing highest alterations at recommended fat levels.

\section{Propiedades fisicoquímicas y nutricionales de productos extrudidos y popeados de sorgo integral de diferentes variedades}

\section{Emilce Elina Llopart}

Directora: Dra. Silvina Rosa Drago

Lugar de realización: Laboratorio de Cereales y Oleoginosas, Instituto de Tecnología de Alimentos, Facultad de Ingeniería Química, Universidad Nacional del Litoral.

Fecha de defensa: 15/12/2015.

\section{Resumen}

Las recomendaciones dietéticas de la Estrategia Mundial dirigida a las poblaciones que sugieren el consumo de cereales integrales son apropiadas para la población Argentina. El sorgo es una fuente principal de energía, proteínas, vitaminas y minerales. Además, este cereal presenta una comprobada versatilidad bajo condiciones agronómicas muy adversas. Una ventaja muy importante es que no posee gluten y se lo puede utilizar como materia prima para el desarrollo de alimentos destinados a la creciente población celíaca.

El objetivo de esta tesis fue evaluar los efectos de dos procesos de expansión: la extrusión y el popeado en las propiedades fisicoquímicas y nutricionales de harinas integrales precocidas de sorgo de distinta variedad o cultivar, a fin de estudiar la factibilidad de incorporar al sorgo en la formulación de alimentos aptos para celíacos.

Se analizaron híbridos de sorgo (14 sorgos blancos: SB y 14 sorgos rojos: SR) y se clasificaron como bajos en taninos 0 sin taninos condensados, con lo cual eran aptos para el consumo humano. Fueron evaluados en cuanto a su composición química respecto a: proteínas (PR), extracto etéreo (EE), cenizas (CZ), minerales ( $F e, Z n$, $\mathrm{Ca}, \mathrm{Cu}, \mathrm{K}, \mathrm{Mg}, \mathrm{Na}$ y P), Ácido Fítico (AF), Polifenoles Totales (PFT), Polifenoles Libres (PF Lib) y Polifenoles Ligados (PF Lig). Los valores hallados se encontraron dentro de los rangos informados en la bibliografía. De las determinaciones químicas realizadas se observó que PR, EE, CZ, AF, Fe Zn, Ca, Cu, $\mathrm{K}, \mathrm{Mg}, \mathrm{Na}$ y $\mathrm{P}$ presentaron distribución normal. Se observaron diferencias según se trataba SB o SR en los contenidos de Fe, $\mathrm{Zn}, \mathrm{Na}, \mathrm{AF}, \mathrm{Cu}, \mathrm{y} \mathrm{P}$, siendo los 3 primeros mayores en SB. Por otra parte, PFT, PF Lib 
y PF Lig no presentaron distribución normal y además, hubo diferencias según el color del grano. Al analizar sus medianas, todas fueron mayores para los SR. Esto es de esperar ya que los sorgos con testa pigmentada poseen más PF. Los contenidos de PF Lig fueron, en todos los casos, mayores a PF Lib.

El estudio de las características fisicoquímicas y nutricionales permitió caracterizar cultivares argentinos de SR y SB aptos para el consumo humano.

Por otra parte, se estudiaron y definieron condiciones de trabajo en tecnologías de expansión como el popeado y la extrusión de granos enteros de sorgo que permitieron obtener alimentos e ingredientes de grano entero con buenas propiedades fisicoquímicas y sensoriales. El proceso de popeado generó reducción de CZ, FDT y minerales, y mayores pérdidas de $\mathrm{CAO}$, mientras que la extrusión aumentó en mayor medida la DFe y DPR. El mayor GC en popeado fue para el SB y el mayor GC en extrusión fue para el SR.

Además, se observó una relación entre algunas características fisicoquímicas y la capacidad de popear. Se definió un indicador de la aptitud para el popeado que será útil en la elección de variedades para obtener "palomitas de sorgo".

Se seleccionaron condiciones de extrusión para obtener productos extrudidos que fueron evaluados utilizando un modelo de ratas en crecimiento. El consumo de dichos expandidos manifestó interesantes propiedades saciógenas, fermentación colónica, efecto antioxidantes a nivel colónico, menor actividad de enzimas cecales negativas y disminución de triglicéridos plasmáticos, principalmente en el caso de sorgo rojo, lo cual se adjudicó al mayor contenido de polifenoles.
Ambos procesos tecnológicos de expansión permitieron obtener productos a partir de sorgos integrales y con posibilidades de uso en la elaboración de alimentos sin TACC.

\section{Summary}

Physicochemical and nutritional properties of extruded and popped whole grain sorghum of different varieties

Global Strategy Dietary Recommendations directed to populations suggests the consumption of whole grains. Sorghum is a major source of energy, protein, vitamins and minerals and has proven agronomic versatility under very adverse conditions. A very important advantage of sorghum is that it has not gluten and can be used as ingredient for the development of foods for the growing celiac population. The aim of this thesis was to evaluate the effects of two expansion processes: extrusion and popping on physicochemical and nutritional properties of precooked whole grain flours from different sorghum variety or cultivars, in order to study the feasibility of incorporating sorghum in formulations of suitable foods for celiac people. Expansion working conditions of technologies such as extrusion and popping of whole grain sorghum were studied and defined. They will provide whole grain foods and ingredients with good physicochemical and sensory properties. A relationship among certain physicochemical properties and popping capacity was observed. An indicator of fitness for popping that will be useful in choosing varieties for "pop sorghum" was defined. Extrusion conditions were selected to obtain expanded products which were evaluated using a growing rat model. The consumption of such extrudates showed interes- 
ting satiety properties, colonic fermentation, antioxidant properties at colonic level, lower activity of negative cecal enzymes and lower plasmatic triacylglicerides, mainly in the case of red sorghum which was attributed to the higher content of phenolics.

\section{Respuestas biológicas de ensambles de aves no-paseriformes a la variación espacio-temporal de ambientes acuáticos a escalas local y regional en la planicie de inundación del Paraná Medio}

\section{Rodrigo Ezequiel Lorenzón}

rodrigo_lorenzon@hotmail.com

Director: Dr. Adolfo H. Beltzer

Co-Director: Dra. Paola M. Peltzer

Lugar de realización: Instituto Nacional de Limnología (CONICET-UNL). Laboratorio de Ornitología. Facultad de Bioquímica y Ciencias Biológicas. Universidad Nacional del Litoral

Fecha de defensa: 17-03-2015

\section{Resumen}

El río Paraná Medio presenta una extensa planicie de inundación que se desarrolla en dirección norte-sur siguiendo un gradiente latitudinal y climático. En este estudio se evaluaron las respuestas de las aves no-paseriformes a la variación latitudinal de este corredor fluvial (i.e., cambios regionales) así como a la variación de la composición del paisaje y a los cambios hidrológicos del río. Para esto se realizaron muestreos en humedales de la planicie de inundación del río Paraná Medio seleccionando 60 puntos de conteo. Estos puntos fueron ubicados en cuatro localidades (15 puntos en cada una) distribuidas a lo largo de este corredor fluvial de modo de obtener una representación de los cambios locales de los ensambles (i.e., cambios espacio-temporales dentro de cada localidad) así como de los cambios latitudinales (i.e., cambios entre localidades). Los muestreos fueron repetidos 16 veces cada 45 días y durante dos años (2011-2013) de modo de cuantificar los cambios temporales de los ensambles. La composición del paisaje, definida como la proporción de diferentes unidades de vegetación y ambiente (UVAs) fue descripta a campo, dentro del radio de observación de los puntos de conteo, y a través de imágenes satelitales, considerando diferentes extensiones alrededor de cada punto de conteo. La composición y estructura de los ensambles variaron a lo largo del corredor fluvial aunque no presentaron un patrón latitudinal. Los resultados indicaron que la riqueza y composición de los ensambles locales a lo largo del río Paraná Medio serían el resultado de la influencia conjunta del pool regional de especies y de las condiciones ambientales locales representadas principalmente por la heterogeneidad y composición de las UVAs. La estructura y composición de los ensambles varió en función de la heterogeneidad ambiental de la planicie de inundación indicando que ésta representa un factor fundamental para el mantenimiento de la biodiversidad de los sistemas fluviales. Los ensambles presentaron una mayor diversidad en aquellos sitios con mayor canti- 
dad de UVAs. El análisis especie-específico mostró que esto podría relacionarse con que diferentes especies se asocian con diferentes UVAs y a que existen especies asociadas a sitios ambientalmente más heterogéneos. Al considerar la composición del paisaje descrita de manera remota mediante imágenes satelitales se encontró igualmente que la composición del paisaje en extensiones locales sería importante para dar cuenta de los cambios en la abundancia relativa de las especies que conforman los ensambles. No obstante, en este caso la presencia-ausencia de las especies se presentó mayormente asociada a la composición del paisaje en extensiones más amplias que las correspondientes a los sitios de muestreo (al menos 50,3 ha.). A escala temporal, la riqueza, abundancia y diversidad de los ensambles decrecieron del primer al segundo año en las cuatro localidades sugiriendo que los cambios interanuales pueden estar relacionados con factores regionales. Los patrones de variación temporal intra-anual de la estructura de los ensambles, por el contrario, difirieron entre las localidades, sugiriendo que estos cambios se deben a las características locales del ambiente y/o a la influencia de procesos estocásticos. Los patrones temporales a escala regional de la riqueza, abundancia y diversidad fueron muy similares entre los dos años considerados, sugiriendo que sería posible identificar patrones de variación intra-anual definidos si se considera al sistema fluvial en conjunto. La riqueza y diversidad de los ensambles se redujo con el incremento del nivel hidrométrico, por lo que esta variable dio cuenta de parte de los cambios temporales de los ensambles. El análisis del efecto del nivel hidrométrico sobre el paisaje sugirió que esta relación negativa puede estar relacionada con el anegamiento de ciertas unidades ambientales que, no obstante, no implican una reducción significativa de la heterogeneidad espacial. Las playas, por ejemplo, se relacionaron positivamente con la riqueza y diversidad de los ensambles y presentaron una probabilidad de ocurrencia menor durante niveles hidrométricos relativamente altos debido a que serían cubiertas por el agua. Puesto que el estudio incluyó solamente un período hidrológico ordinario del río, estos resultados indicaron que cambios de baja magnitud en el régimen hidrológico pueden generar importantes cambios en la diversidad de aves del sistema fluvial. Los resultados mostraron un ajuste especie-específico de las aves con la heterogeneidad espacio-temporal de la planicie de inundación. Las variaciones del nivel hidrométrico y de la proporción relativa de las UVAs determinarían respuestas cuyas características dependen de los requerimientos de hábitat de las especies. No obstante, sólo algunas de las especies que obtienen su alimento nadando y caminando tendrían mayores y menores frecuencias de ocurrencia, respectivamente, frente al incremento del nivel hidrométrico del río. De este modo, el uso de hábitat de las especies en base al que han sido definidos los gremios de aves en la planicie de inundación representa información a partir de la cual podría determinarse parcialmente como éstas responden a los cambios naturales y antropogénicos del sistema fluvial.

\section{Summary}

Biological responses of non-passerine bird assemblages to spatio-temporal variation of wetlands at local and regional scales in the floodplain of the Middle Paraná River. 
We studied the variation of non-passerine bird assemblages along the Middle Paraná River. Bird surveys were conducted in 60 point counts located in wetlands along the fluvial system. Points were positioned in four localities (15 points each one) distributed along the riparian corridor to assess the local (i.e., within each locality) and the regional (i.e., among localities) changes of the bird assemblages. Surveys were repeated every 45 days for two years (2011-2013) to assess temporal changes. Structure and composition of assemblages varied as a function of environmental heterogeneity indicating that it is a fundamental factor for the maintenance of biodiversity in the system. Richness, abundance and diversity decreased from the first to the second year in the four localities indicating that interannual changes may be related to regional factors. By contrast, intra-annual variations in the structure of the assemblages differed among localities suggesting that these changes reflect local conditions and/or the influence of stochastic processes. Hydrometric level accounted for a portion of temporal changes since richness and diversity decreased with the increase of this variable. Since the study involved only an ordinary river hydroperiod, these results indicated that low-magnitude changes in the hydrological regime of the river can generate significant changes in bird diversity of the riparian system. Results showed a species-specific adjustment of birds with the spatio-temporal heterogeneity of the floodplain. The use of information on trophic habitat requirements by the different species represent information from which bird responses to natural and anthropogenic changes can be partially determined.

\section{Pichones parasitados por Philornis (Diptera: Muscidae): importancia y potencial impacto del cambio climático}

\section{Darío Ezequiel Manzoli}

dmanzoli@fcv.unl.edu.ar

Director: Dr. Pablo Martín Beldomenico

Lugar de realización: Laboratorio de Ecología de Enfermedades, Instituto de Ciencias Veterinarias del Litoral (Universidad Nacional del Litoral - Consejo Nacional de Investigaciones Científicas y Técnicas)

Fecha de defensa: 28 de marzo de 2014

\section{Resumen}

El Género Philornis, es un grupo de moscas de la Familia Muscidae que en su estadio larvario parasitan aves y pueden ser altamente perjudiciales para los pichones.
La mayor parte del conocimiento actual se limita a Philornis downsi, parásito semihematófago que, luego de ser introducido a las Galápagos, es una amenaza para la conservación de los pinzones de Darwin. El resto de las especies del género (principalmente moscas que producen miasis cavitaria), a pesar de existir evidencia de producir efectos deletéreo, han sido poco estudiadas especialmente en Sudamérica. Algunas investigaciones de tipo observacional han evaluado los efectos letales y subletales de las miasis cavitaria por Philornis, pero los resultados han diferido y la evidencia de causalidad presentada es débil. 
Tales análisis no controlaron por fenómenos de enmascaramiento e interacción. Por otra parte, se ha comprobado que el incremento de precipitaciones y de temperaturas por lo general se correlacionan positivamente con prevalencia e intensidad de ectoparásitos, pudiendo incluir en estas generalizaciones al parasitismo por Philornis. Para establecer los determinantes de este patógeno se requiere de estudios con datos meteorológicos de corto plazo. Evidencia anecdótica sugiere que la ocurrencia de estas miasis está en incremento en el centro de Argentina. Considerando que el clima ha estado cambiando en la región (mayores temperaturas ambientales y precipitaciones), la ecoepidemiología de estos parásitos debería estudiarse en el sur de Sudamérica, ya que el calentamiento global puede causar la expansión geográfica de estos parásitos hacia el sur. El objetivo general de la presente tesis es determinar si el cambio climático representa una amenaza para la conservación de aves Passeriformes. Para lo cual se llevaron a cabo estudios observacionales longitudinales y experimentales.

Al momento de determinar cuáles son los factores que están asociados con la abundancia parasitaria de Philornis torquans se generaron estudios a distintos niveles de organización biológica. Cuando se evaluó a nivel de individuo, se encontró que existen diferencias entre las especies de hospedadores y fue importante la edad en que alcanzaban el máximo de parasitismo. Las principales variables que favorecieron el parasitismo a nivel de microhábitat, fueron la menor altura de los bosques autóctonos y la presencia de bosques exóticos establecidos. Por último, a nivel de comunidad, la abundancia de Philornis estuvo significativa y positivamente asociada a la densidad de
Pi. sulphuratus y precipitaciones pasadas. Para medir el impacto de la miasis sobre las crías de aves se estableció tanto en un estudio longitudinal como experimental. En el primero, se observó un efecto negativo diferencial dependiendo el hospedador analizado, el mayor impacto fue en las especies de Phacellodomus (Ph. ruber y Ph. sibilatrix) siendo menor en Pi. sulphuratus, mientras que aquellos pichones que sobrevivieron tuvieron un crecimiento más lento. Al analizar los resultados de un experimento, de tipo ensayo a campo, cuyo tratamiento fue la extracción diaria de larvas de Philornis, hubo diferencias marcadas al comparar la sobrevida entre los dos hospedadores más parasitados, mientras que en Phacellodomus ruber los controles tuvieron 5 veces más probabilidades de morir que los tratados, esto no se observó en Pitangus sulphuratus. Al evaluar los parámetros hematológicos, en ambas especies la miasis se asoció con anemia, pero sólo en $P h$. ruber los controles presentaron una marcada leucocitosis, acompañada con heterofilia y linfopenia, importante comparado con los tratados. Por último, se muestra un modelo matemático compartimental de tipo SIS acoplado con SIR, que es el primero que se realiza para miasis.

\section{Summary}

Nestling parastic of Philornis (Diptera: Muscidae): significance and potencial impact of climate change.

The larvae of Philornis's gender (Diptera:Muscidae) parasitize nestling birds and could be highly detrimental. Some studies have evaluated the negative effects of cavitary myiasis by Philornis, but the results have differed and evidence of causality is scarce. Moreover, it has been found that 
increasing temperature and rainfall usually are positively correlated with the abundance of ectoparasites. Ecoepidemiological studies of these parasites in Southern South America are necessary because temperature and rainfall are increasing. The objective of this thesis is to determine if climate change could be poses a threat to the conservation of passerine birds. To determine factors associated with Philornis's abundance, studies at different levels of biological organization has been done. At individual level, we found that exist differences between host species and their age. In the microhabitat level, the parasit- ism was favored by lowest height of native forests and the presence of exotic forests. Finally, at the community level, the abundance of this larva was positively associated with the density of Pitangus sulphuratus and past rainfall. To measure the impact of this miasis on the nestlings we established longitudinal and experimental studies. In the first case, a negative differential effect depended on the host. The minimal impact was found in Pi.sulphuratus but in the case of Phacellodomus's species it was notoriously bigger. Finally, a compartment mathematical model of SIS coupled with SIR, is the first one done for a myiasis

\section{Diseño, modelado y optimización de foto-bioreactores destinados al cultivo de microalgas para diferentes aplicaciones tecnológicas}

\section{Ignacio Niizawa}

ignacioniizawa@gmail.com

Director: Dr. Horacio Antonio Irazoqui

Lugar de realización: Laboratorio de Operaciones y Procesos Biotecnológicos. Facultad de Bioquímica y Ciencias Biológicas. Universidad Nacional del Litoral

Fecha de la defensa: 27/3/2015

\section{Resumen}

La biotecnología aplicada al cultivo de algas representa un importante campo de estudio en la actualidad. Los productos y aplicaciones que pueden desarrollarse a partir de ellas son muy diversos: producción de biodiesel a partir de sus aceites; bioremediación de efluentes líquidos y gaseosos; la utilización de la propia biomasa para consumo humano o animal; obtención de productos bio-activos para la indus- tria farmacéutica; obtención de aceites omega 3; etc. Las microalgas unicelulares se encuentran entre los organismos autotróficos más productivos de la naturaleza debido a su elevada eficiencia fotosintética. Sin embargo, actualmente las eficiencias y productividades alcanzadas en grandes reactores son dos o tres órdenes de magnitud menores que el valor teórico esperado. Debido a esto, es importante lograr la optimización tanto de la intensidad de energía que reciben los cultivos de microalgas, como del perfil de longitudes de onda de dicha radiación. Es por ello que se propone en la presente tesis llevar adelante un estudio integral acerca de la influencia del perfil de radiación recibido por un cultivo sobre el crecimiento de las microalgas a través del modelado del campo de energía radiante en los foto-bio-reactores a fin 
generar modelos intrínsecos que permitan proponer y verificar herramientas aptas para el diseño, optimización y cambio de escala de foto-bio-reactores, destinados a la propagación de microalgas y producción de metabolitos derivados de ellas con diferentes aplicaciones de interés tecnológico.

\section{Summary}

Design, modeling and optimization of photo-bio-reactors for microalgal cultivation for different technological applications.

Microalgal Biotechnology represents an important field of study in the present. The products and applications that can be developed from them are very diverse: biodiesel production from their oils; bioremediation of liquid and gaseous effluents; the use of biomass for human or animal nutrition; bioactive products for the pharmaceutical industry; omega 3 fatty acids; etc. Unicellular microalgae are among the most productive autotrophic organisms in nature due to their high photosynthetic efficiency. However, currently efficiencies and productivities achieved in large reactors are two to three orders of magnitude smaller than the theoretical value expected. Because of this, it is important to achieve the optimization of radiation conditions (both the intensity of the energy and the wavelengths profile) received by microalgae cultures. It is therefore proposed in this thesis to develop a comprehensive study on the influence of radiation profile received by the photo-bio-reactor on microalgal growth through the radiant energy field modeling in order to generate intrinsic models to propose and verify appropriate tools for the design, optimization and scaling of photo-bio-reactors, for microalgal culture and the production of metabolites with different applications of technological interest.

\section{Síntesis controlada y caracterización de complejos látex-proteína para detección de toxoplasmosis aguda mediante pruebas de inmunoaglutinación}

\section{Leandro E. Peretti}

Iperetti@santafe-conicet.gov.ar , leandroperetti@yahoo.com.ar

Director / Co-Director: Dr. Luis M Gugliotta / Dra. Verónica DG Gonzalez

Lugar de realización: Grupo de Polímeros y Reactores de Polimerización, Instituto de Desarrollo Tecnológico para la Industria Química (INTEC), UNL-CONICET. Facultad de Bioquímica y Ciencias Biológicas. Universidad Nacional del Litoral

Fecha de la defensa: 30/03/2015

\section{Resumen}

La Toxoplasmosis, enfermedad causada por el parásito Toxoplasma gondii, generalmente se presenta asintomática o con síntomas inespecíficos, y en la mayoría de los pacientes no es necesario ningún tipo de intervención médica. Sin embargo, si es adquirida durante la etapa de gestación puede provocar aborto, inducir malformaciones, hidrocefalia, macro o microcefalia y lesiones oculares. El diagnóstico adecuado y el tratamiento oportuno constituyen la mejor manera tanto para prevenir la transmisión transplacentaria, como para redu- 
cir la morbimortalidad y las secuelas de la Toxoplasmosis congénita.

El diagnóstico de la Toxoplasmosis se basa fundamentalmente en el análisis serológico, que consiste en la búsqueda de anticuerpos (Ac) específicos en suero. Una forma de detectar Ac específicos es mediante la técnica de inmunoaglutinación (IA), la cual emplea partículas de látex como soporte de biomoléculas con el objetivo de amplificar la reacción antígeno-anticuerpo (Ag-Ac). En una reacción de IA, los complejos látex-proteína (CLP) son reconocidos por los Ac específicos presentes en los sueros de pacientes positivos y forman una red de aglutinación, que puede ser observada a simple vista o empleando técnicas instrumentales. La IA presenta las ventajas de ser rápida, sencilla, económica y de gran utilidad para su utilización en tamizajes. En el caso particular de la Toxoplasmosis, cuando el suero de una embarazada resulta positivo, es necesario determinar si se trata de una infección reciente o pasada.

El objetivo de esta Tesis fue obtener CLP útiles como reactivos de IA en la detección de Toxoplasmosis recientemente adquirida. El trabajo se dividió en cuatro etapas:

I) Síntesis controlada de partículas de látex de poliestireno (PS) y de partículas con morfología núcleo-coraza (o "coreshell"), con tamaños, grupos funcionales y densidades de carga superficial controlados. Se sintetizaron látex cuasi-monodispersos de PS en un rango de diámetros de 100-1100 nm, por polimerización en emulsión o en dispersión. Los látex de PS se emplearon luego como siembras en copolimerizaciones en emulsión de estireno y de un monómero funcional; empleándose ácido metacrílico, para brindar a las partículas de funcionalidad carboxilo, o glici- dil metacrilato, para obtener partículas con funcionalidad epoxi. Los látex obtenidos se caracterizaron, determinándose el tamaño de partícula, las densidades de carga y de grupos funcionales superficiales, la concentración crítica de coagulación y las propiedades electrocinéticas (movilidad electroforética y potencial Zeta).

II) Producción y cuantificación de las proteínas antigénicas del Toxoplasma gondii. Se trabajó con una mezcla de proteínas obtenidas a partir de la lisis del parásito (homogenato); y con dos proteínas recombinantes de fase aguda, cuya obtención involucró su expresión a partir de bacterias transformadas, su purificación y su cuantificación.

III) Preparación de los CLP mediante la adsorción física y/o la unión covalente de las proteínas antigénicas, sobre las partículas previamente sintetizadas. Se evaluó el efecto del tipo de superficie, del tamaño y de la densidad de grupos funcionales, sobre la cantidad de proteína acoplada. Se realizó la caracterización de los complejos y se evaluó la antigenicidad de las proteínas unidas a las partículas de látex para determinar si las mismas mantenían su capacidad de reconocimiento de Ac específicos luego de la sensibilización de las partículas.

IV) Aplicación de los distintos CLP en ensayos de IA. La reacción Ag-Ac de IA se siguió instrumentalmente por turbidimetría, midiendo el cambio de absorbancia que ocurre al entrar en contacto el CLP con el suero. En una primera instancia se utilizaron sueros controles, clasificados por técnicas de referencia en tres grupos: agudos, crónicos y negativos, para determinar las condiciones óptimas de reacción, es decir, aquellas que permiten la mayor discriminación de los sueros agudos respecto de los sueros crónicos y negativos. Posteriormente, los CLP se enfren- 
taron a un panel de sueros para evaluar su potencial aplicación como reactivos de IA.

Los trabajos realizados permitieron obtener partículas de látex sensibilizadas con Ag del T. gondii que fueron evaluadas en ensayos de IA frente a un panel de sueros. Los resultados obtenidos bajo las condiciones experimentales ensayadas, indican que los CLP podrían resultar adecuados como reactivos de IA para detectar la fase aguda de la Toxoplasmosis, aunque para confirmar estos resultados se debería evaluar un panel de sueros mayor.

\section{Summary}

Controlled synthesis and characterization of latex-protein complexes for the detection of acute toxoplasmosis by immunoagg/utination assays.

Toxoplasmosis is a worldwide disease caused by the parasite Toxoplasma gondii, which acquired during gestation can cause abortion or induce malformations, hydrocephalus, macro or microcephaly and eye damage. Precise diagnosis and quick treatment are the best way to prevent transplacental transmission and reduce morbidity and mortality.

Diagnosis of Toxoplasmosis is mainly based on serological tests, which involves searching for specific antibodies (Ab). One way to detect specific Ab in serum is by the latex agglutination test (LAT), which employs latex particles as support of biomolecules, in order to amplify the antigen-antibody (Ag$A b)$ reaction. In the immunoagglutination assays (IA), latex-protein complexes (LPC) are recognized by specific $A b$ present in the sera of infected patients, thus producing immunoagglutination. LAT is a fast and cheap detection method, which results particularly useful for screening purposes.

The goal of this Thesis was to obtain LPC useful as LAT for detecting recently acquired Toxoplasmosis. The experimental work was divided into four stages: I) controlled synthesis, cleaning and characterization of functionalized latexes; II) production and quantification of antigenic proteins of $T$. gondii; III) synthesis of the LPC, where latex particles were sensitized with the antigenic proteins by physical adsorption or covalent coupling; and IV) application of the LPC in IA. As a general conclusion it was possible to obtain latex particles coated with $T$. gondii antigens which were evaluated on IA assays against a reduced panel of sera. Under the tested experimental conditions, the LPC were suitable as LAT reagents for detecting the acute phase of Toxoplasmosis, although they should be evaluated against a larger panel of sera to confirm the obtained results.

\section{Diseño, construcción y evaluación de un inmunógeno específico para la prevención de mastitis bovina producida por Streptococcus uberis}

\section{Melina Perrig \\ meliperrig@gmail.com \\ Director / Co-Director: Dra. Carolina Veaute / Dra. María Sol Barbagelata}

Lugar de realización: Laboratorio de Tecnología Inmunológica. Facultad de Bioquímica y Ciencias Biológicas. Universidad Nacional del Litoral. Santa Fe, Argentina. Fecha de la defensa: 29 de Junio de 2015. 


\section{Resumen}

La mastitis bovina es una importante enfermedad que sufre el ganado lechero. Es la responsable de grandes pérdidas económicas en los productores y la industria láctea, una de las principales actividades económicas de Argentina. El Streptococcus uberis no logro ser controlado con las medidas establecidas por los organismos internacionales y nacionales. La alta incidencia de este patógeno tanto en Argentina como en otros países del mundo y la falta de eficacia en las terapias antibióticas en períodos de mayor incidencia, enfoca el problema en la búsqueda de una terapia alternativa, tendiendo al menor uso de antibióticos, como son las terapias inmunoprofilácticas. En la actualidad no existe una vacuna en el mercado. Los resultados experimentales obtenidos hasta el momento con diferentes diseños de vacunas, muestran un control parcial de la infección. Debido a que S. uberis es un patógeno ambiental, el tratamiento y la prevención de infecciones provocadas por este microorganismo deben dirigirse a una multitud de cepas diferentes. Estas observaciones señalan la necesidad de explorar los aislamientos regionales para la elección de candidatos vacunales adecuados. El objetivo central de este trabajo fue desarrollar un inmunógeno específico para la prevención de mastitis bovina producida por S. uberis. Para alcanzar ese objetivo, el trabajo se dividió en tres etapas. En una primera instancia se analizó la variabilidad clonal de $S$. uberis de aislamientos representativos de las principales cuencas lecheras del país, así como la prevalencia y conservación de los genes de virulencia (pauA y sua), dos factores de virulencia que participan en la etapa inicial de la infección intramamaria por S. uberis. Dos técnicas de tipificación molecular (PFGE y RAPD-PCR) fueron utilizadas para establecer la relación genética entre los aislamientos. El análisis determinó una gran variabilidad clonal entre los aislamientos y no logró asociar ningún patrón clonal a un tipo de mastitis. A pesar de la alta variabilidad clonal, los genes estudiados se detectaron en la mayoría de los aislamientos. Más aún, presentaron secuencias con alta identidad a nivel nucleotídico, tanto entre cepas regionales como con cepas internacionales. En la segunda etapa de este trabajo, se propuso realizar una evaluación funcional e inmunológica, en un modelo murino, de los antígenos seleccionados. Para eso, se obtuvieron en forma recombinante, 4 fracciones de SUAM (SUAM-1fr, SUAM2fr, SUAM-3fr, SUAM-4fr) y PauA (PauAr). Se demostró que todos los antígenos eran inmunogénicos en ratones. Con respecto a PauAr, se mostró que era funcionalmente activa, y los anticuerpos generados eran específicos. En cuanto a las fracciones de SUAM, se evaluó su capacidad de unión a lactoferrina (LF), y respecto a los anticuerpos generados, se analizó su capacidad de mediar la fagocitosis, su especificidad y su capacidad de inhibir la adherencia a células epiteliales mamarias. Los anticuerpos anti-SUAM-1fr mostraron mayor especificidad contra la proteína wild type, mayor interferencia en la adherencia de S. uberis a células epiteliales mamarias y mayor capacidad opsónica respecto a las otras fracciones. Asimismo, se observó que SUAM1 fr y SUAM-4fr mostraron una tendencia a unirse en mayor proporción a la LF. En base a estos resultados se determinó a la región SUAM-1fr como potencial componente de una vacuna a subunidad. Finalmente, se evaluó la respuesta humoral en vaquillonas 
preñadas utilizando 2 dosis a los 45 y 15 días previos a la fecha probable de parto, de una formulación conteniendo SUAM-1fr y PauAr, con tres adyuvantes diferentes. La respuesta en sangre mostró niveles de anticuerpos superiores a los controles en todos los grupos inmunizados. La inmunización elevó los niveles de $\lg _{2}$ específicos. Además, se observó que los adyuvantes conteniendo saponina generaron una respuesta humoral superior a los obtenidos con el adyuvante clásico hidróxido de aluminio. En leche, también se obtuvieron anticuerpos específicos hacia los dos inmunógenos, y la respuesta no mostró diferencias significativas entre los tres adyuvantes. Estos resultados demostraron que la incorporación de más de un antígeno a la formulación, no altera la inmunogenicidad individual de cada molécula. Además, indicarían que la saponina estaría potenciando la respuesta inmune. En conclusión los dos candidatos vacunales son conservados y prevalentes entre una amplia diversidad clonal de cepas de Argentina, y son capaces de generar una respuesta inmune significativa. Más aún los resultados indicarían una región dentro de la molécula SUAM, que cumpliría un rol importante dentro del mecanismo patogénico propuesto. Además, las inmunizaciones en bovinos, con el prototipo vacunal indicarían que ambas proteínas, formuladas con el adyuvante adecuado, son capaces de inducir una respuesta inmune que resulta alentadora para ensayos futuros de vacunas hacia IIM por S. uberis.

\section{Summary}

Design, construction and evaluation of a specific immunogen for prevention of bovine mastitis caused by Streptococcus uberis.
Bovine mastitis is an important disease of dairy cattle. The objective of this work was to develop a specific immunogen for the prevention of bovine mastitis caused by $S$. uberis. First, the clonal variability of $S$. uberis isolated, as well as the prevalence and conservation of virulence genes (pauA and sua) were analyzed. The analysis found a clonal variability between isolates, however it was observed that both genes were prevalent and conserved. Then, functional and immunological evaluations of the selected antigens in a murine model were done. Four fractions of SUAM (SUAM-1fr, SUAM2fr, SUAM-3fr and SUAM-4fr) and PauA (PauAr) recombinant proteins were obtained. All antigens were immunogenic in mice and induced specific antibodies. The antiSUAM antibodies were studied for their ability to mediate phagocytosis, their specificity and ability to inhibit adherence to mammary epithelial cells. Anti-SUAM-1fr antibodies showed more specificity against wild type protein, more interference in adhesion of $S$. uberis and greater opsonic activity, compared to other fractions. Based on the results obtained, SUAM-1fr was chosen as a potential region for a subunit vaccine. Finally, the humoral response in pregnant heifers with a formulation containing SUAM-1fr and PauAr, with three different adjuvants, was evaluated. Immunization elevated the levels of specific antibodies in blood and milk. Furthermore, saponin-containing adjuvants induced a stronger humoral response than those obtained with the $\mathrm{Al}(\mathrm{OH})_{3}$.

In conclusion, two highly conserved and prevalent vaccine candidates are able to generate a significant immune response. Also, both proteins formulated with the adequate adjuvant, can generate an immune response. 


\section{Desarrollo de un inmunógeno multicomponente prototípico para el control de infecciones causadas por Staphylococcus aureus}

\section{Nazarena Pujato}

nazarenapujato@gmail.com

Director / Co-Director: Dr. Iván S. Marcipar/

Dr. Luis F. Calvinho

Lugar de realización: Facultad de Bioquímica y Ciencias Biológicas. Universidad Nacional del Litoral. Ciudad de Santa Fe, Provincia de Santa Fe, Argentina.

Fecha de la defensa: 25/09/2015

\section{Resumen}

La mastitis bovina produce grandes pérdidas económicas al sector lechero a nivel muncial, siendo Staphylococcus aureus el principal agente causante de la enfermedad. La falta de efectividad de las medidas de control y el creciente interés por reducir el uso de antibióticos en animales de consumo humano, incentivan el desarrollo de vacunas preventivas contra la mastitis estafilocócica. A pesar de las décadas de investigación en el tema, no existe a la fecha una formulación efectiva capaz de prevenir nuevas infecciones bacterianas. Sin embargo, los antecedentes han demostrado que se obtienen mayores niveles de protección con inmunógenos multicomponentes, producidos mediante la tecnología del ADN recombinante y formuladas con un adyuvante de nueva generación.

En el marco de esta tesis, se desarrolló una vacuna a subunidades, que incluye distintos antígenos bacterianos que intervienen en mecanismos de virulencia claves durante los diferentes estadíos de la infección por $S$. aureus. Entre las diversas moléculas candidatas, se seleccionaron las proteínas de adhesión ClfA y FnBPA de importancia en las etapas tempranas de la interacción parásito-hospedador. Los polisacáridos capsulares CP5 y CP8, que facilitan la diseminación de la bacteria y la evasión del sistema inmune. La proteína IsdH, involucrada en el metabolismo del hierro y, por lo tanto, está asociada a la capacidad de la bacteria de sobrevivir en el hospedador. Finalmente la hemolisina Btox, responsable de causar daños en el hospedador.

Los polisacáridos CP5 y CP8 se seleccionaron por su mayor prevalencia en la cuenca lechera Argentina. Estos se purificaron a partir de cepas productoras y se conjugaron a una proteína transportadora (la ASH) para conferirle propiedades inmunogénicas. En este trabajo se propuso y evaluó una técnica de conjugación que utiliza p-benzoquinona, la cual ha sido descripta como una metodología sencilla, reproducible, de alto rendimiento y económica, que para nuestro conocimiento, no ha sido aplicada previamente para la preparación de vacunas conjugadas. Se optimizó la conjugación de los CPs bacterianos a albúmina sérica humana ( $\mathrm{ASH}$ ) obteniéndose un alto rendimiento de productos conjugados $\left(\mathrm{CP} 5-\mathrm{ASH}_{\mathrm{PBQ}}\right)$. El conjugado $\mathrm{CP} 5-\mathrm{ASH}_{\mathrm{PBQ}}$, formulado con el adyuvante AIF, fue evaluado en ratones luego de 4 dosis intraperitoneales. La inmunización demostró ser eficiente en generar una respuesta T-dependiente, basada en altos títulos de anticuerpos $\lg _{\text {tota }}$ l, y elevados niveles de $\lg _{1}$, 
$\lg _{2 a}$ e $\lg G_{3}$. Además, los animales inoculados con el conjugado respondieron frente a un desafío con el CP5 nativo, realizado a los 3 meses post- inmunización, indicando que el CP5-ASH ${ }_{\mathrm{PBQ}}$ es capaz de desarrollar memoria inmune contra el polisacárido. Los resultados indicaron que los CPs conjugados mediante la técnica de la PBQ, constituyen candidatos prometedores para la formulación de la vacuna multicomponente contra S. aureus.

Los antígenos de naturaleza proteica se produjeron de manera recombinante y se evaluó la inmunogenicidad de cada uno de ellos en un modelo animal murino. Todas las moléculas obtenidas generaron altos títulos de anticuerpos $\operatorname{lgG}_{\text {total }}$ incluso a dosis bajas. Esto tiene importancia para el desarrollo de formulaciones multicomponentes, ya que permite la combinación de un mayor número de antígenos sin producir aumentos marcados en las dosis proteicas a administrar.

Todas las moléculas obtenidas se combinaron en dos inmunógenos multicomponentes, VacR1 (rClf, rFnBP y rBtox) y VacR258 (rClf, rFnBP, rBtox, rlsdH, CP5ASHPBQ y CP8-ASHPBQ), empleando el adyuvante de nueva generación ISCOMATRIXTM ${ }^{\mathrm{TM}}$ La inmunización de vaquillonas preñadas con dos dosis subcutáneas de VacR1 y VacR258 (administradas 45 y 15 días previos al parto), generó importantes respuestas humorales tanto en sangre como en leche, durante el período de mayor susceptibilidad a adquirir infecciones por $S$. aureus. Ambas formulaciones aquí evaluadas, generaron altos niveles de $\operatorname{lgG}_{2}$ en sangre, principal opsonina para neutrófilos bovinos. Además, la inmunización produjo aumentos significativamente los niveles de $\lg _{1}$ e $\lg G_{2}$ en leche respecto del grupo con- trol, reforzando la protección contra potenciales infecciones bacterianas de la glándula mamaria en el período post-parto. Los anticuerpos obtenidos mostraron ser efectivos en bloquear las funciones de sus proteínas blanco, contribuyendo a reducir marcadamente la capacidad de la bacteria de adherirse e invadir el tejido epitelial mamario, a neutralizar la actividad hemolítica de la Btox nativa y promoviendo la fagocitosis de la bacteria por PMN bovinos. En conclusión, las formulaciones VacR1 y VacR258 ofrecen un gran potencial para proteger contra las infecciones causadas por S. aureus, por lo que constituyen candidatos prometedores a seguir evaluando como vacunas destinadas al control de la mastitis bovina causada por S. aureus.

\section{Summary}

Development of a prototypical multicomponent immunogen for control Staphylococcus aureus infections.

Bovine mastitis produces great economical losses to dairy industry worldwide, being Staphylococcus aureus (S. aureus) the main causative agent of the disease. Lack of effectiveness control measures and the growing interest on reducing antibiotics therapies in animals for human consumption, encourage the development of preventive vaccines against staphylococcal mastitis.

In this thesis, a rational approach has been applied for the development of a $S$. aureus vaccine. They have been selected different bacterial antigens involved in key virulence mechanisms among the differents stages of the infection, with the aim of prevent disease establishment. Protein antigens were produced using recombinat strategies. Whereas polysaccharides antigens were purified from producer strains and were coupled to a car- 
rier protein through an innovative conjugation technique for the preparation of vaccine components. The obtained antigens were formulated in two multicomponents vaccines, denominated VacR1 and VacR258. Immunization of pregnant heifers with these formulations, induced significant humoral responses, both in blood and milk, during the period of increased susceptibility to adquire $S$. aureus infections. Antibodies produced were capable of blocking their target antigens, reducing markadely the hability of the bacteria to invade the mammary epithelial tissue and promoting its cleaning through phagocytosis. In conclusion, both developed formulations are promising vaccine candidates, since they offered a great potential to protect against bovine mastitis caused by $S$. aureus.

\section{Caracterización funcional de los Factores de Transcripción HaWRKY10 y HaWRKY76 de girasol y OsWRKY47 de arroz. Aplicaciones biotecnológicas}

\section{Jesica Raineri}

Jesica_raineri@hotmail.com

Director / Co-Director: Dra. Karina F. Ribichich/ Dra. Raquel L. Chan

Lugar de realización: Instituto de Agrobiotecnología del Litoral. Laboratorio de Biotecnología Vegetal. Facultad de Bioquímica y Ciencias Biológicas. Universidad Nacional del Litoral

Fecha de la defensa: 10/07/2015

\section{Resumen}

Dado el aumento continuo de la población mundial es necesario incrementar la producción de los cultivos que aseguren la alimentación de esta población. Para lograr este objetivo es fundamental conocer el funcionamiento integral de las plantas y sus mecanismos de respuesta a estímulos de distintos tipos. En estas respuestas intervienen factores de transcripción (FTs), proteínas que regulan la expresión de genes blanco y desencadenan cascadas de señalización que llevan o no a la adaptación de las plantas al medio en el que se encuentran.
En este trabajo de Tesis, se eligieron como objeto de estudio tres FTs, dos de girasol (HaWRKY76 y HaWRKY10) y uno de arroz (OsWRKY47). HaWRKY76 le confiere a las plantas de Arabidopsis características agronómicas deseables en condiciones de crecimiento normales y mayor tolerancia al estrés por exceso o defecto de agua. Por otro lado, HaWRKY10 está involucrado en la acumulación y el uso de sustancias de reserva y tiene un papel en la germinación de las semillas. Por su parte, OsWRKY47 tiene un papel en la respuesta de las plantas IPT al estrés hídrico y en su mecanismo de respuesta hay al menos dos genes regulados de forma directa por este FT de transcripción.

Esta caracterización funcional permitió obtener información relevante para la mejor comprensión de los mecanismos de respuesta de estas especies vegetales frente al estrés por exceso y falta de agua y sobre algunos aspectos del desarrollo. El resultado de estos estudios permitió postular a estas tres proteínas como potenciales herramientas biotecnológicas para el fitomejoramiento. 


\section{Summary}

Funtional caracterization of the Transcription Factors HaWRKY10 y HaWRKY76 from sunflower and OsWRKY47 from rice. Biotechnological applications.

Given the increasing world population it is necessary to produce more food for human consumption. To achieve this goal it is essential to gain insights about the mechanisms taking place in plants to deal with different environmental conditions. In these responses are involved a group of proteins called transcription factors (TFs). TFs are proteins that regulate the expression of their target genes and trigger signaling cascades leading or not to the plant adaptation to the environment.

In this Thesis work we studied three TFs belonging to the WRKY family, two of them from sunflower (HaWRKY76 and HaWRKY10) and one from rice (OsWRKY47). HaWRKY76 gives Arabidopsis plants desirable agronomic traits in normal growth and higher stress tolerance in drought or water excess. On the other hand, HaWRKY10 is involved in the accumulation and use of reserve substances and has a role in seed germination. Meanwhile, OsWRKY47 has a role in the response of IPT plants to water stress and their response mechanism involve at least two genes directly regulated by this TF.

Through this study relevant information was obtained for a better understanding of plant response mechanisms, in particular responses to abiotic stress caused by excess and lack of water. Moreover, the involvement of these TFs in some developmental stages was also investigated. To a greater or lesser extent, these three proteins are potential biotechnological tools for crop improvement.

\section{Ácidos grasos trans dietarios: interacción nutricional con diferentes familias de ácidos grasos insaturados}

\section{Juliana Saín}

jsain@fbcb.unl.edu.ar; julianasain@gmail. com

Director: Dr. Claudio A. Bernal / Co-directora: Dra. Marcela A. González.

Lugar de realización: Cátedra de Bromatología y Nutrición. Departamento de Ciencias Biológicas. Facultad de Bioquímica y Ciencias Biológicas. Universidad Nacional del Litoral

Fecha de defensa: 16 de marzo de 2015

\section{Resumen}

En las últimas décadas, ha sido demostrado que consumos elevados de ácidos grasos trans (AGt) incrementan el riesgo de padecer enfermedades cardiovasculares y otras enfermedades crónicas no transmisibles. Estos efectos deletéreos, han sido atribuidos, principalmente, a la alta ingesta de AGt de origen industrial, que contienen una elevada proporción de ácido elaídico (t9-18:1). Sin embargo, las fuentes naturales de AGt, como carne y lácteos derivados de animales rumiantes, poseen una proporción significativa de ácido vaccénico (AV, t11-18:1), el cual puede ser bioconvertido a ácido ruménico (AR, $c 9, t 11-18: 2)$, un conjugado del ácido linoleico, al cual se le han atribuido numerosos efectos funcionales sobre la salud. Por otro lado, las diferentes proporciones relativas de ácidos grasos 
insaturados (AGl) dietarios de las series n-3, n-6 y n-9 podrían ser fundamentales para modular el metabolismo de los AGt, ya que ha sido demostrado que los isómeros de ácidos grasos (AG) podrían interferir en la vía de biosíntesis de ácidos grasos poliinsaturados de cadena larga (LC-PUFA). El presente trabajo de tesis tuvo como objetivo avanzar en el conocimiento de los potenciales efectos metabólico-nutricionales de las interacciones que podrían tener los AGt con aceites ricos en $A G$ conteniendo diferentes proporciones relativas de $A G I$ de las series n-3, n-6 y n-9 en animales de experimentación. Además, es importante analizar esta interacción utilizando niveles de AGt que podrían ser alcanzables por la población y con aceites y grasas disponibles para el consumo humano.

Para lograr dicho objetivo, ratones de la cepa CF1 macho, a dos semanas luego del destete, fueron sometidos a un tratamiento dietario durante 30 días, con alguna de las seis dietas isocalóricas experimentales producto de la combinación de dos variables independientes: fuente de grasa dietaria y presencia de AGt. El nivel de lípidos dietarios fue del $7 \%$, siendo los aceites utilizados: aceite de oliva (O), maíz (M) o canola (C) los cuales proveen distintas proporciones de $A G I$ de las familias n-3, n-6 y n-9; y en el caso de las dietas parcialmente sustituidas con AGt, parte del aceite experimental se sustituyó con aceite vegetal parcialmente hidrogenado (47\% de AGt) para obtener dietas con un 1\% de AGt: oliva + AGt (Ot), maíz + AGt (Mt) y canola + AGt (Ct). Para evaluar parámetros nutricionales se realizaron estudios de ganancia de peso, eficiencia energética de las dietas, composición corporal y retención energética corporal. En referencia al metabolismo lipídico, se pun- tualizó en la incorporación de AG en diferentes tejidos, específicamente retención de AGt, perfiles de lípidos tisulares y séricos, mecanismos de regulación y movilización de triglicéridos (TG) en tejidos y, además, se evaluaron actividades de enzimas reguladoras de la síntesis y oxidación de AG, como así también, la expresión de dichas enzimas y los factores de transcripción que regulan su expresión.

En relación a los principales resultados obtenidos en el trabajo de tesis, pudimos concluir que: 1) ingestas bajas de AGt caracterizadas por una elevada proporción de AV no indujeron los notables efectos deletéreos observados previamente por nuestro grupo y otros autores con dietas ricas en ácido elaídico; 2) las modificaciones en el perfil de AG tisulares dependió más del tipo de $A G I$ dietario que de la presencia de AGt; 3) los AGt individuales se incorporaron en forma diferente en distintos tejidos, y la retención de los mismos fue influenciada por la relación de AGl de las familias n-3, n-6 y n-9; 4) la bioconversión de AV a AR hepática dependió de la proporción de AGl de la grasa dietaria, siendo mayor en los animales alimentados con aceite de oliva y 5) el efecto de los AGt sobre el metabolismo lipídico dependió de la proporción de AGl de la grasa dietaria, presentando mayores alteraciones en los animales alimentados con aceite de oliva y de canola, denotando principalmente una mayor acumulación de TG hepáticos.

Si bien los resultados experimentales en modelos animales no pueden extrapolarse directamente a los seres humanos, el conocimiento de los potenciales efectos metabólico-nutricionales de las interacciones que podrían tener los AGt con aceites ricos en $A G$ con diferentes proporciones relativas 
de AGl de las series n-3, n-6 y n-9, podría ser de gran utilidad para el desarrollo de estrategias nutricionales eficaces para la disminución de la incidencia de alteraciones relacionadas a enfermedades crónicas no transmisibles.

\section{Summary}

Dietary trans fatty acids: nutritional interaction with the various families of unsaturated fatty acids.

The deleterious effects associated with a high intake of trans fatty acids (TFA) have been mainly attributed to the intake of industrial TFA containing a high proportion of elaidic acid $(t 9,18: 1)$. However, natural TFA, present in the meat and dairy products from ruminant animals, contain a significant proportion of vaccenic acid (VA, t11-18:1), which could be bioconverted to rumenic acid (RA, c9, t11-18:2), a conjugated linoleic acid with numerous functional effects on health. Furthermore, the different proportions of dietary unsaturated fatty acids (UFA) could be essential to modulate the TFA metabolism. The objective was to investigate the potential metabolic-nutritional effects of the interaction between TFA and oils containing different n-3, n-6 and n-9 UFA proportions in mice. From the obtained results, we could conclude that: 1) low intakes of TFA rich in VA did not induce the deleterious effect associated with diets rich in elaidic acid observed by our group and other research teams; 2) the alterations in the tissue FA profile depended on the dietary UFA rather than on the presence of TFA; 3 ) the levels of individual TFA incorporation depended on the tissue and their retention was influenced by the UFA relations; 4) the bioconversion of VA to RA in liver was dependent on the dietary UFA ratios, being higher in olive oil fed animals than on those fed maize or canola; 5) the TFA effect on the lipid metabolism depended on the dietary UFA proportion, being exacerbated in olive and canola fed animals, thus showing a hepatic TG accumulation.

\section{Producción de hidrógeno a partir de glicerol: desarrollo de catalizadores inorgánicos y de sistemas biológicos}

\section{Esteban Andrés Sanchez}

esanchez@fiq.unl.edu.ar

Director: Dr. Raúl Alberto Comelli

Co-Director: Dr. Alejandro José Beccaría

Lugar de realización: Laboratorio 67, Instituto de Investigaciones en Catálisis y Petroquímica - INCAPE (FIQ-UNL, CONICET) y Laboratorio de Fermentaciones (FBCB-UNL).

Fecha de la defensa: 30 de Marzo de 2015.

\section{Resumen}

La dependencia de la humanidad por los combustibles fósiles genera grandes pro- blemas hacia el medioambiente. Las reservas mundiales de combustibles fósiles son limitadas, y desde hace algunas décadas las tecnologías que aprovechan las fuentes alternativas de energía, como la biomasa, aumentaron de manera notable. La producción de biocombustibles líquidos ha experimentado un constante crecimiento, destacándose en gran medida la producción de biodiesel, proceso que genera glicerol como principal subproducto. Este compuesto posee un bajo precio en el mercado global, convirtiéndolo en una materia prima 
altamente valorizable. En nuestro país, las principales plantas productoras de biodiesel se encuentran en la Provincia de Santa Fe, concentradas en la zona del Gran Rosario, disponiendo de grandes cantidades de glicerol con potencial de utilización. La industria de producción de hidrógeno también viene experimentando un constante incremento, siendo obtenido principalmente a partir de combustibles fósiles. Por lo tanto, resulta muy interesante el desarrollo de un proceso que permita la utilización del glicerol para la obtención de hidrógeno. Entre diferentes tecnologías utilizadas en la actualidad, el diseño y aplicación de un sistema de reacción que utiliza catalizadores químicos mediante el reformado en fase gas es factible, debido a la sencilla operabilidad e importante eficiencia de reacción, permitiendo el análisis de los procesos que producen la disminución de la actividad catalítica. Respecto a los sistemas biológicos, el empleo de medios de cultivo con microorganismos que producen la fermentación de los sustratos agregados, presenta como principales facilidades la reducida cantidad de recursos necesarios para permitir el crecimiento celular y un consumo energético notablemente inferior que para los procesos químicos. Sin embargo, resulta de gran relevancia efectuar la búsqueda de formulaciones óptimas de medio de cultivo que permitan alcanzar mayores rendimientos hacia los productos de interés. Durante el proceso de reformado en fase gas del glicerol se generó hidrógeno como producto principal. El aumento de la carga de precursor metálico en los catalizadores preparados favoreció la conversión a productos gaseosos a menores temperaturas, facilitando la eliminación parcial del depósito carbonoso formado sobre el mate- rial durante la reacción. En la fermentación del glicerol, la cepa identificada como promisoria para la producción de hidrógeno a partir de glicerol presentó un mayor consumo de glicerol y producción acumulada de hidrógeno que la cepa identificada como control, y la optimización de la formulación de un medio de cultivo demostró que el crecimiento celular puede ser mejorado, permitiendo incrementar el consumo del sustrato adicionado y la producción del compuesto de interés en forma gaseosa. La aplicación de procesos catalíticos y biológicos permitió la utilización de una materia prima renovable, económica y de elevada disponibilidad en el país, favoreciendo la creciente industria de producción del biodiesel e incrementando notablemente el valor de los productos generados.

\section{Summary}

Hydrogen production from glycerol: inorganic catalysts and biological systems development.

World reserves of fossil fuels are limited, and it has generated a significant increase in the use of biomass technologies. The production of liquid biofuels has increased, especially the biodiesel generation, process that allows obtain glycerol as main by-product. The low cost of glycerol positions it as a highly recoverable raw material, and the Province of Santa Fe has a great potential due to the presence of the main biodiesel plants in the country. The hydrogen production industry has experienced a steady increase, and this compound is obtained mainly from fossil fuels. Among different technologies, the glycerol steam reforming using chemical catalysts presents simple operability and important reaction efficiency. In biological systems, the substrate fermen- 
tation employing a culture medium with microorganisms demand few resources and has lower energy consumption. However, is highly relevant to optimize the culture medium formulations. The glycerol steam reforming generated hydrogen as the main product, where a greater loading of catalytic precursor favored the conversion to gaseous products at lower temperatures, with partial removal of carbonaceous deposit formed. In the glycerol fermentation, a strain promising for hydrogen production showed higher glycerol consumption and cumulative hydrogen production that the control strain, and optimization of the culture medium formulation showed an improvement in cell growth, with higher substrate consumption and hydrogen production. Both catalytic and biological processes allowed to use a renewable and economical raw material of high availability in the country, favoring the growing biodiesel industry and significantly increasing the value of generated products.

\section{Bifidobacterias de leche materna. Aspectos microbio- lógicos, tecnológicos y funcionales}

\section{María Florencia Zacarías}

florzacarias@yahoo.com.ar / mfzacarias@ conicet.gov.ar

Director / Co-Director: Dr. Celso Gabriel Vinderola / Dr. Jorge Alberto Reinheimer Lugar de realización: Instituto de Lactología Industrial (INLAIN, UNL-CONICET). Facultad de Ingeniería Química. Universidad Nacional del Litoral

Fecha de la defensa: 20/03/2015

\section{Resumen}

La leche materna humana puede ser considerada como el alimento funcional natural por excelencia ya que no sólo tiene un alto valor nutritivo sino que además es una fuente de bacterias, como bifidobacterias y lactobacilos, que son transferidas de la madre al hijo, y ayudan en la colonización temprana del tracto gastrointestinal y la correcta maduración del sistema inmune de la mucosa del recién nacido. Los probióticos son definidos como microorganismos vivos que, cuando son consumidos en cantidades adecuadas, confieren un efecto saludable al hospedador. Cepas específicas de bifidobacterias y lactobacilos son las más estudiadas y comercializadas como probióticos. En este contexto, el uso como probióticos de este tipo de microorganismos (provenientes de leche materna), para su incorporación a alimentos funcionales, resulta de potencial interés científico y para la industria de alimentos.

Para que un microorganismo sea considerado probiótico, fundamentalmente tres aspectos deben ser evaluados: seguridad, funcionalidad y resistencia a procesos tecnológicos. En la presente Tesis Doctoral se buscó avanzar en el conocimiento sobre los microorganismos de la leche materna, particularmente bifidobacterias, y evaluar su potencial para ser utilizadas como probióticos. Se realizaron aislamientos a partir de muestras de leche materna de madres de la ciudad de Santa Fe, en las primeras 8 semanas posparto. Aislamientos presuntivos de bifidobacterias (y lactobacilos) fueron estudiados microbiológica y genéticamente (RAPD PCR) e identificados por secuen- 
ciación del ARNr 16S. Se conformó una colección de bacterias de leche materna, compuesta por 6 cepas de bifidobacterias correspondientes a 3 especies distintas: Bifidobacterium animalis subsp. lactis, Bifidobacterium longum y Bifidobacterium dentium, además de 4 cepas de lactobacilos. A continuación se estudió el potencial tecnológico (Capítulo II) y funcional (Capítulo III) de las cepas de bifidobacterias, principalmente B. animalis subsp. lactis INL1. En la caracterización tecnológica se evaluó el desarrollo de las cepas en diferentes medios de cultivo y su resistencia al almacenamiento, digestión gástrica simulada (DGS) y diferentes procesos de deshidratación. Se observó un comportamiento cepa-dependiente y en particular $B$. animalis subsp. lactis INL1 demostró ser una cepa robusta, capaz de ser desarrollada en medios de cultivo de bajo costo con buenos rendimientos, alta resistencia a la deshidratación, al almacenamiento y a la DGS. Además, se realizaron ensayos preliminares de secado spray (SS) en leche descremada a escala laboratorio e industrial. En ambos casos se obtuvieron polvos con humedades satisfactorias y sobrevida aceptable, lo que indicaría que $B$. animalis subsp. lactis INL1 posee potencial tecnológico para ser incorporada, mediante SS, a una fórmula infantil.

La seguridad y caracterización funcional de los aislamientos de leche materna se evaluó a través de ensayos in vitro e in vivo. Se analizó la resistencia de las cepas de bifidobacterias a antibióticos (ATB), su hidrofobicidad superficial y resistencia a digestión gastrointestinal simulada, con resultados acordes a lo reportado previamente. También se evaluó la capacidad de algunas cepas de sintetizar derivados conjugados del ácido linoleico (CLA) y del ácido linolénico, siendo $B$. animalis subsp. lactis INL2 la cepa con mayor capacidad. Para evaluar la funcionalidad en ensayos in vivo en ratones, se seleccionó la cepa B. animalis subsp. lactis INL1. Se la utilizó en un modelo de tránsito intestinal, administrada como cultivo puro o acompañada por inulina (prebiótico). También se analizó su capacidad inmunoestimuladora a nivel intestinal y su capacidad protectora frente a un patógeno intestinal (SalmoneIla), cuando se la administró como cultivo fresco o sometido a tratamientos tecnológicos, y a diferentes concentraciones y períodos de tiempo. La cepa fue capaz de estimular la respuesta inmune mucosa mediada por IgA y demostró capacidad protectora frente a una cepa de Salmonella enterica ser. Typhimurium, disminuyendo los indicadores de daño inflamatorio y la translocación del patógeno a sitios extra intestinales, como bazo e hígado. Cuando fue sometida a tratamientos tecnológicos, mantuvo algunas de sus propiedades, principalmente en su forma de cultivo SS. En su conjunto, los resultados obtenidos del estudio funcional in vivo de B. animalis subsp. lactis INL1 permiten postularla como una bacteria potencialmente probiótica, con capacidad de estimular la función inmune en el intestino y protegerlo parcialmente frente a una infección con Salmonella ser. Typhimurium. Estos hechos, sumado a su robustez ante diversos procesos tecnológicos, en escala laboratorio e industrial, además de la capacidad de mantener su funcionalidad cuando es sometida a los mismos, particularmente el secado spray, posicionan a $B$. animalis subsp. lactis INL1 como el primer aislamiento de leche materna humana del país con potencial probiótico demostrado en estudios in vivo y con potencial de ser 
transferida a la industria, una vez realizados los estudios clínicos en humanos necesarios para verificar los resultados obtenidos en este trabajo de Tesis.

\section{Summary}

Bifidobacteria from human breast milk. Microbiological, technological and functional aspects.

Breast milk is a complex and complete food, essential for the normal development in the first years of life. Besides its high nutritional value it is a source of bacteria that are naturally transferred from mother to child. These bacteria, including bifidobacteria and lactobacilli, are responsible in part for the gastrointestinal colonization and adequate maturation of the mucosal immune system of the newborn. Probiotics are defined as live microorganisms which, when administered in adequate amounts, confer a health benefit on the host. The aim of this Doctoral Thesis was to study the microorganisms, particularly bifidobacteria, present in the human breast milk, in order to evaluate their technological and functional potential to be used as probiotics. The results showed the presence in breast milk of bifidobacteria and lactobacilli only until week 4 postpartum. The bifidobacteria isolates were studied and some safety, functional and technological characteristics were determined. Resistance to antibiotics was consistent with those reported for other authors. Low hydrophobicity and satisfactory resistance to gastrointestinal digestion were observed in general for all strains of $B$. animalis subsp. lactis and $B$. longum. The results of this work support the idea that not every single isolate from breast milk should be considered as potential probiotic, as many difficulties might arise for managing these strains outside its natural ecological niche. Finally, the findings of this work related to the technological performance and functional properties of $B$. animalis subsp. lactis INL1 suggest that this breast milk strain is a good candidate for probiotic use. 